\title{
Integrated statistical modelling of spatial landslide probability
}

\section{Mergili ${ }^{1,2}$ and H.-J. Chu ${ }^{3}$}

${ }^{1}$ Geomorphological Systems and Risk Research, Department of Geography and Regional Research, University of Vienna, Universitätsstraße 7, 1190 Vienna, Austria

${ }^{2}$ Institute of Applied Geology, University of Natural Resources and Life Sciences (BOKU), Peter-Jordan-Straße 70, 1190 Vienna, Austria

${ }^{3}$ Department of Geomatics, National Cheng Kung University, 1 University Road, 701 Tainan, Taiwan

Received: 26 August 2015 - Accepted: 3 September 2015 - Published: 24 September 2015 Correspondence to: M. Mergili (martin.mergili@boku.ac.at)

Published by Copernicus Publications on behalf of the European Geosciences Union.

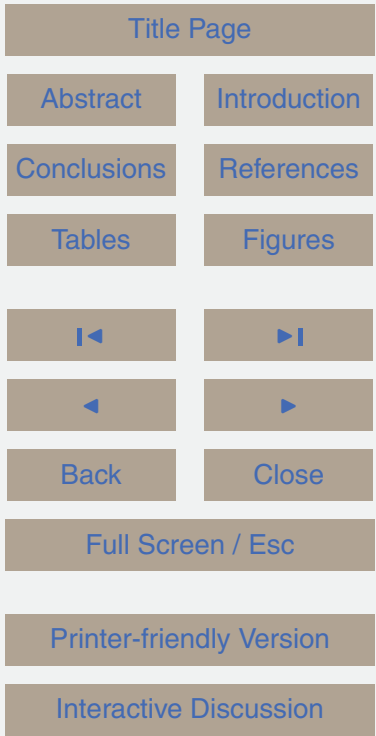

Integrated statistical modelling of spatial landslide probability

M. Mergili and H.-J. Chu

Title Page

Abstract

Introduction

Conclusions

Tables

Full Screen / Esc

nteractive Discussion 


\section{Abstract}

Statistical methods are commonly employed to estimate spatial probabilities of landslide release at the catchment or regional scale. Travel distances and impact areas are often computed by means of conceptual mass point models. The present work intro-

\section{duces a fully automated procedure extending and combining both concepts to compute} an integrated spatial landslide probability: (i) the landslide inventory is subset into release and deposition zones. (ii) We employ a simple statistical approach to estimate the pixel-based landslide release probability. (iii) We use the cumulative probability density function of the angle of reach of the observed landslide pixels to assign an impact probability to each pixel. (iv) We introduce the zonal probability i.e. the spatial probability that at least one landslide pixel occurs within a zone of defined size. We quantify this relationship by a set of empirical curves. (v) The integrated spatial landslide probability is defined as the maximum of the release probability and the product of the impact probability and the zonal release probability relevant for each pixel. We demonstrate the approach with a $637 \mathrm{~km}^{2}$ study area in southern Taiwan, using an inventory of 1399 landslides triggered by the typhoon Morakot in 2009. We observe that (i) the average integrated spatial landslide probability over the entire study area corresponds reasonably well to the fraction of the observed landside area; (ii) the model performs moderately well in predicting the observed spatial landslide distribution; (iii) the size of the release zone (or any other zone of spatial aggregation) influences the integrated spatial landslide probability to a much higher degree than the pixel-based release probability; (iv) removing the largest landslides from the analysis leads to an enhanced model performance.

\section{NHESSD}

3, 5677-5715, 2015

Integrated statistical modelling of spatial landslide probability

M. Mergili and H.-J. Chu

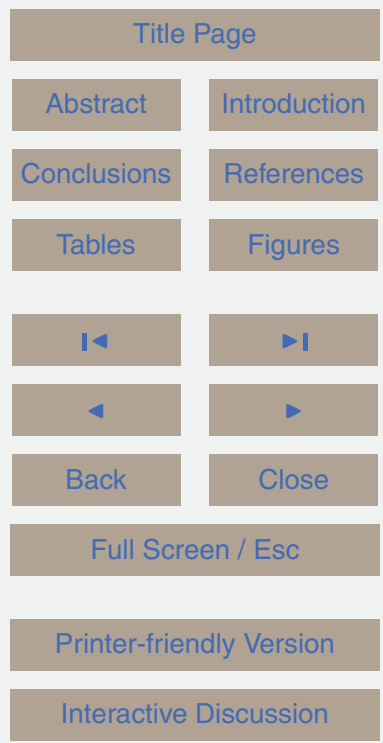




\section{Introduction}

Overviews of spatial landslide probability (susceptibility) at catchment or regional scales are useful for hazard indication zoning and for prioritizing target areas for risk mitigation. Computer models making use of geographic Information Systems (GIS) are 5 commonly employed to produce such overviews (Van Westen et al., 2006). Physicallybased modelling of landslide susceptibility - also with reasonably complex modelling tools - has become an option also for large areas from a purely technical point of view (Mergili et al., 2014a, b). However, the parameterization of such models remains a challenge, limiting the quality of the results obtained. For this reason, statistical methods often coupled with stochastic concepts - are commonly employed to relate the spatial patterns of landslide occurrence to those of environmental variables, and to estimate landslide susceptibility by applying these relationships (Guzzetti, 2006). A broad array of statistical methods for landslide susceptibility analysis has been developed, documented by a large bunch of publications (e.g. Carrara et al., 1991; Baeza and Coromi15 nas, 2001; Dai et al., 2001; Lee and Min, 2001; Brenning, 2005; Saha et al., 2005; Guzzetti, 2006; Komac, 2006; Lee and Sambath, 2006; Lee and Pradhan, 2007; Yalcin, 2008; Yilmaz, 2009; Nandi and Shakoor, 2010; Yalcin et al., 2011; Petschko et al., 2014). However, such methods only concern the release of landslides whilst they disregard their propagation.

20 Whilst advanced physically-based models for landslide propagation (e.g. Christen et al., 2010a, b) are usually employed for local-scale studies, conceptual approaches have been developed to analyze and to estimate travel distances and impact areas at broader scales. Some build on the angle of reach or related parameters (e.g. Scheidegger (1973) for rock avalanches; Zimmermann et al. (1997) and Ricken25 mann (1999) for debris flows; Corominas et al. (2003) for various types of landslides; Noetzli et al. (2006) for rock/ice avalanches), others consist in semi-deterministic models employing the concept of Voellmy (1955) (Perla et al., 1980; Gamma, 2000; Wichmann and Becht, 2003; Horton et al., 2013). Mergili et al. (2015) have recently pre-
NHESSD

3, 5677-5715, 2015

Integrated statistical modelling of spatial landslide probability

M. Mergili and H.-J. Chu

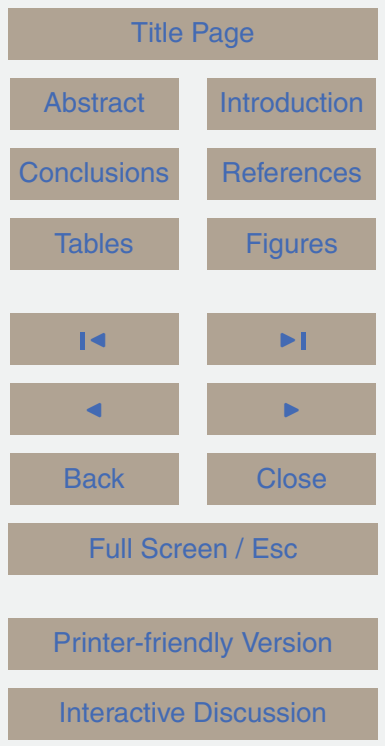


sented an automated approach to statistically derive cumulative density functions of the angle of reach from a given landslide inventory, and to apply these functions to compute a spatially distributed impact probability. Modelling approaches considering both the release and the propagation of landslides do exist (Mergili et al. (2012) and Hor5 ton et al. (2013) for debris flows; Gruber and Mergili (2013) for various high-mountain processes). However, they yield deterministic results distinguishing areas with an impact expected from those with no impact expected, or qualitative scores.

Integrated automated approaches to properly estimate the spatial probability of a given area to be affected by a landslide - considering both release and propaga10 tion - are still missing. The present work attempts to fill this gap by combining the two newly developed open source software tools r.landslides.statistics and r.randomwalk. We will next introduce our modelling strategy (Sect. 2) and the study area in Taiwan (Sect. 3). After presenting (Sect. 4) and discussing (Sect. 5) the results we will conclude with a set of key messages (Sect. 6).

15 Within the present article we use the term "landslide" in a broad sense, including all relevant types of gravitational mass movements.

\section{Modelling strategy}

\subsection{General model layout}

We propose an integrated statistical procedure (containing stochastic elements) to compute the spatial probability of a given area (technically, a given GIS pixel) to be affected by a landslide either through its release or through its propagation. We first consider release and propagation separately and finally combine the two concepts. The entire work flow is illustrated in Fig. 1, its components are introduced in detail in Sects. 2.2-2.6.

Two newly developed raster modules of the open source software package GRASS GIS 7 (Neteler and Mitasova, 2007; GRASS Development Team, 2015) are combined:
NHESSD

3, 5677-5715, 2015

Integrated statistical modelling of spatial landslide probability

M. Mergili and H.-J. Chu

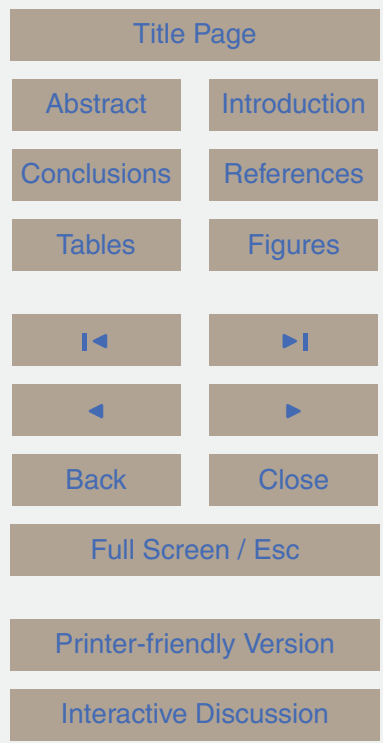


- r.landslides.statistics allows inventory subsetting, estimation of the spatial probability of landslide release, and the generation of a zonal probability function.

- r.randomwalk, introduced by Mergili et al. (2015), employs sets of constrained random walks to route hypothetic mass points down through the digital elevation model (DEM) and assigns an impact probability to each pixel. The cumulative probability density function (CDF) used is derived from the analysis of the observed landslides. Further, r.randomwalk includes an algorithm to combine release probabilities and impact probabilities, making use of the zonal probability function derived with r.landslides.statistics.

10

Both tools build on a combination of the Python and $\mathrm{C}$ programming languages. The $R$ software environment for statistical computing and graphics (R Core Team, 2015) is used for built-in validation and visualization functions. r.landslides.statistics and r.randomwalk can be started in a fully non-interactive way i.e. all parameters are passed as command line arguments. This strategy enables a straightforward combination of 15 multiple runs of the two models at the script level.

An issue of central importance consists in the strict separation of the data used for model development and the data used for model application and evaluation. In this sense, most operations are performed either for the model development area (MDA) or for the model evaluation area (MEA), but not for both. The only exception from this rule 20 applies to the initial step of inventory subsetting.

All probabilities used in the context of the present work are summarized in Table 1.

\subsection{Inventory subsetting}

Landslide inventories often suffer from a missing - or unsatisfactory - subsetting into release, transit and deposition areas. The reason for this problem, which applies also to our case study, is not necessarily related to deficient mapping efforts, but rather to the impossibility to identify each zone in the field or from remotely sensed data. Appropriate subsetting, however, is required before using the inventory for statistical analyses of 5681

\section{NHESSD}

3, 5677-5715, 2015

Integrated statistical modelling of spatial landslide probability

M. Mergili and H.-J. Chu

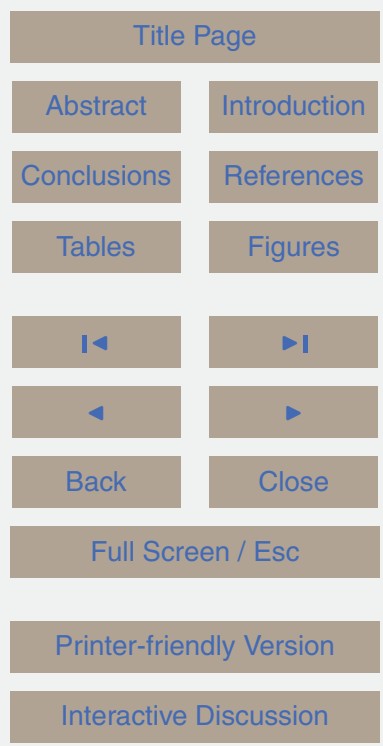


landslide release or propagation. We therefore suggest a reproducible procedure to deal with this problem.

We analyze the geometric properties of all landslides in a given inventory in terms of inclination, minimum and maximum elevation, elevation range, central, maximum and 5 average 2-D and 3-D length and width, 2-D and 3-D areas. Lengths and widths are defined as Euclidean distances (the central 2-D and 3-D lengths $L_{2-D}$ and $L_{3-\mathrm{D}}$ as well as the elevation range $H$ are shown in Fig. 2). On this basis we compute the height ratio $r_{H}$ for each observed landslide pixel:

$$
r_{\mathrm{H}}=\frac{H_{\mathrm{p}}-H_{\min }}{H_{\max }-H_{\min }},
$$

where $H_{\mathrm{p}}$ is the elevation at the considered pixel, $H_{\text {min }}$ is the minimum elevation of the landslide and $H_{\max }$ is the maximum elevation of the landslide (see Fig. 2).

In the present work, we consider all observed landslide pixels with $r_{H} \geq r_{\mathrm{R}}$ as release pixels and all observed landslide pixels with $r_{\mathrm{H}} \leq r_{\mathrm{D}}$ as deposition pixels. $r_{\mathrm{R}}$ and $r_{\mathrm{D}}$ are defined by the user. All other observed landslide pixels are considered as unknowns regarding release and deposition. Following these rules, we obtain three landslide inventory maps:

1. observed release areas (ORA), where all release pixels are considered observed positives (OP), the rest of the landslide areas are considered no data, and all non-landslide pixels are considered observed negatives (ON);

2. observed deposition areas (ODA), where all deposition pixels are considered OP, the rest of the landslide areas are considered no data, and all non-landslide pixels are considered $\mathrm{ON}$;

3. observed impact areas (OIA), where all landslide pixels are considered OP, and all non-landslide pixels are considered $\mathrm{ON}$.

These definitions prevent us from including pixels in the statistical analysis and the validation procedure we can neither assign to the ORA nor to the ODA. To ensure 5682

\section{NHESSD}

3, 5677-5715, 2015

Integrated statistical modelling of spatial landslide probability

M. Mergili and H.-J. Chu

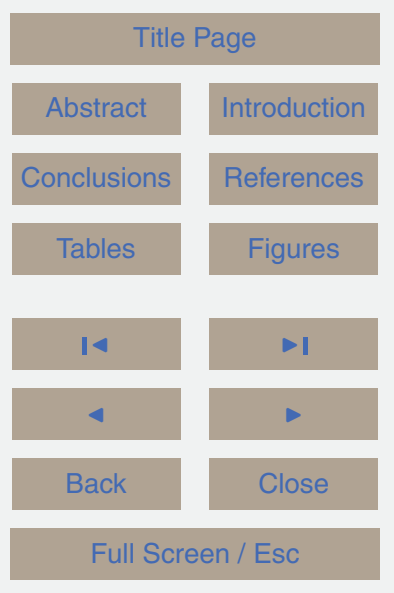

Printer-friendly Version

Interactive Discussion 
excuding all uncertain pixels we have to chose conservative values of $r_{\mathrm{R}}$ and $r_{\mathrm{D}}$, resulting in a decreased number of OP pixels used for the statistical analyses and their validation.

\subsection{Pixel-based release probability}

5 Statistical analyses of landslide spatial release probability (landslide susceptibility) have been treated exhaustively in previous studies (see Sect. 1 for references). In the context of the present work we are bound to a method yielding spatial probabilities in the range $0-1$. In this sense, we employ a simple approach building on the spatial overlay of classified predictor maps. Considering separately each of the resulting combinations of predictor classes, we compute the fraction $f_{\mathrm{R}}$ of observed landslide release pixels related to all pixels. For this step we consider only the MDA. Building on the assumption that possible future landslides in the MEA are spatially related to the predictors in the same way as the observed landslides in the MDA, the release probability $P_{\mathrm{R}}$ (see Table 1) for each pixel in the MEA is set to the value of $f_{\mathrm{R}}$ associated to the corresponding combination of predictor classes.

The true positive (TP), true negative (TN), false positive (FP) and false negative (FN) pixel counts are derived for selected levels of $P_{\mathrm{R}}$. An ROC Curve is produced by plotting the true positive rate TP/OP against the false positive rate FP/ON.

\subsection{Zonal release probability}

20 It is useful for many purposes to work with pixel-based spatial release probabilities $\left(P_{\mathrm{R}}\right)$. They can be averaged in order to characterize the spatial probability of landslides for any type of zone (such as slope units, catchment basins, administrative entities or larger pixels). However, the average of $P_{\mathrm{R}}$ over a certain zone does not tell us how likely it is that a landslide occurs in a zone at all. For this purpose we introduce the zonal release probability $P_{\mathrm{Rz}}$ (see Table 1 ) which increases with study area size. When considering one single pixel, $P_{\mathrm{RZ}}=P_{\mathrm{R}}$. For large areas (mountainous catchments or
NHESSD

3, 5677-5715, 2015

Integrated statistical modelling of spatial landslide probability

M. Mergili and H.-J. Chu

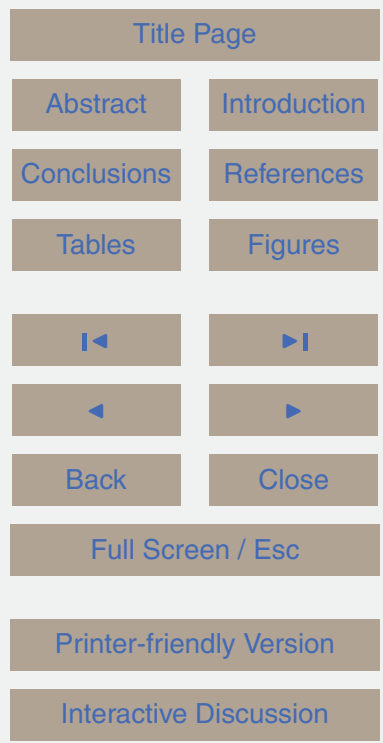


entire countries) $P_{\mathrm{Rz}}=1$ as there will always be at least one landslide pixel. $P_{\mathrm{Rz}}$ may be useful for assessing how likely it is that a certain object (such as a road) is affected by a landslide at all. It is further the appropriate parameter when validating landslide probability at the level of slope units or other entities larger than single pixels. In the 5 present work it is needed primarily as a basis to compute the integrated spatial landslide probability $P_{\mathrm{L}}$ (see Sect. 2.6). It is further used to aggregate the model results at the level of slope units.

$P_{\mathrm{RZ}}$ cannot be computed in a fully analytic way. We suggest an empirical approach to approximate $P_{\mathrm{RZ}}$ (Fig. 3):

1. a subset of the MDA with a randomized size and randomized centre coordinates is selected. $P_{\mathrm{RO}}$ is the observed pixel-based spatial probability of landslide release in this subset (i.e. the fraction of ORA pixels out of all pixels);

2. within this subset, a set of sub-subsets with constant zone size $Z$ and randomized centre coordinates is tested for the presence of observed landslide release pixels. The observed zonal release probability $P_{\mathrm{RzO}}$ is defined as the fraction of subsets with at least one observed landslide release pixel (see Fig. 3a);

3. (2) is repeated for a large number of sets of sub-subsets covering a broad range of $Z$.

(1)-(3) are repeated for a large number of random subsets of the MDA.

20 This procedure results in a line cloud of $P_{\mathrm{RZO}}$ plotted against $Z$ (one line for each subset; Fig. 3b). A logistic regression is fitted to the average value of $P_{\mathrm{RZO}}, \mu_{\mathrm{PRZO}}$, for each tested value of $Z$ :

$\mu_{\mathrm{PRZO}}(Z)=\frac{\left(1-\mu_{\mathrm{PRO}}\right)}{1+e^{-\left(a_{2}+a_{3} Z\right)}}+\mu_{\mathrm{PRO}}$

where $a_{2}$ and $a_{3}$ are the regression coefficients and $\mu_{\mathrm{PRO}}$ is the fraction of the observed landslide area within the considered zone. We will come back to the function introduced in Eq. (2) in Sect. 2.6.

\section{NHESSD}

3, 5677-5715, 2015

Integrated statistical modelling of spatial landslide probability

M. Mergili and H.-J. Chu Title Page

Abstract Introduction Conclusions References Tables Figures

14

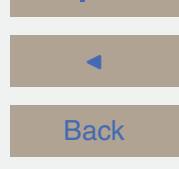
$\rightarrow 1$

Full Screen / Esc

Printer-friendly Version

Interactive Discussion 


\subsection{Impact probability}

The tool r.randomwalk (Mergili et al., 2015) is employed for routing mass points representing hypothetic landslides through the DEM. The specific impact probability $P_{\mathrm{IR}}$ describes the probability of an arbitrary impact pixel to be hit by a mass point routed

5 from a defined release pixel through the DEM. The impact probability $P_{1}^{*}$ or $P_{1}$ results from the spatial overlay of all relevant values of $P_{\mathrm{IR}}$ at a certain pixel (see Table 1). We define $P_{\mathrm{IR}}$ on the basis of the angle of the path $\omega$ between the release pixel and a possible impact pixel. This approach follows the concept of the angle of reach (Heim, 1932; Fig. 4). $P_{1}$ is computed in three steps:

1. The CDF describing the probability that a moving mass point starting from an arbitrary release pixel leaves the OIA of the same landslide at or below a certain threshold of $\omega$ is derived for the MDA. This is done by back-calculating the observed angles of reach $\omega_{\text {OT }}$ for all observed landslides (see Fig. 4a) and analyzing the resulting probability density (see Fig. $4 b$ ).

2. The CDF is then employed to compute $P_{\mathrm{IR}}$ with regard to all observed release pixels in the MEA and evaluated against the ODA by means of an ROC Plot (see Sect. 2.3). For those pixels with impacts from more than one release pixel, $P_{1}^{*}$ takes the maximum value out of all relevant values of $P_{\mathrm{IR}}$ (see Fig. 4c).

3. The same CDF is used for computing $P_{\mathrm{IR}}$ with regard to all pixels in the MEA. For reasons to be explained in Sect. 2.6, for those pixels with impacts from more than one release pixel $P_{\mathrm{l}}$ takes the average value of all relevant values of $P_{\mathrm{IR}}$.

\subsection{Integrated spatial landslide probability}

The integrated spatial landslide probability $P_{\mathrm{L}}$ approximates the spatial probability that a landslide coincides spatially with an arbitrary pixel of the MEA, either through its release or through its impact (see Table 1 ). In principle, $P_{\mathrm{L}}$ is computed by multiplying

\section{NHESSD}

3, 5677-5715, 2015

Integrated statistical modelling of spatial landslide probability

M. Mergili and H.-J. Chu

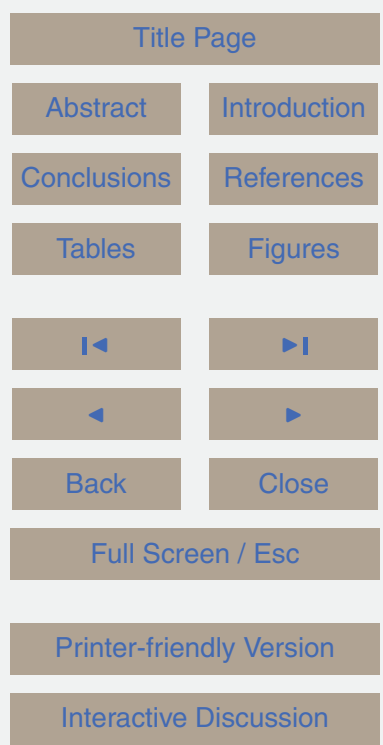


a release probability and an impact probability. Obviously, a simple overlay of $P_{\mathrm{R}}$ and $P_{1}$ would be useless. Instead, we have to consider for each impact pixel with $P_{1}>0$ the zonal release probability $P_{\mathrm{Rz}}$ of the possible release zone (Fig. 5) relevant for this pixel. $Z$ and the associated value of $\mu_{\mathrm{PR}}$ (see Sect. 2.4) refer to the entire set of release 5 pixels which may propagate all the way to the impact pixel. I.e. $P_{\mathrm{RZ}}$ has to be computed separately for each impact pixel.

For this purpose, we come back to the function introduced in Eq. (2). Thereby we assume that the shape of the logistic regression function is insensitive to the zonal average of the computed values of $P_{\mathrm{R}}, \mu_{\mathrm{PR}}$, of any arbitrary subset of the study area 10 with zone size $Z$ (see Fig. 3c):

$$
\frac{1-P_{\mathrm{RZ}}(Z)}{1-\mu_{\mathrm{PRZO}}(Z)} \sim \frac{1-\mu_{\mathrm{PR}}}{1-\mu_{\mathrm{PRO}}} \text {. }
$$

Reformulating Eq. (3), $P_{\mathrm{RZ}}(Z)$ is computed as

$P_{\mathrm{RZ}}(Z) \sim 1-\left(1-\mu_{\mathrm{PRZO}}(Z)\right) \frac{1-\mu_{\mathrm{PR}}}{1-\mu_{\mathrm{PRO}}}$.

For those pixels where $P_{\mathrm{RZ}} \cdot P_{\mathrm{I}}<P_{\mathrm{R}}, P_{\mathrm{L}}$ is set to $P_{\mathrm{R}}$. For all other pixels, $P_{\mathrm{L}}$ is set to the 15 product of $P_{\mathrm{Rz}}$ and $P_{1}$ :

$P_{\mathrm{L}}=\max \left(P_{\mathrm{R}}, P_{\mathrm{RZ}} \cdot P_{\mathrm{l}}\right)$.

The resulting raster map of $P_{\mathrm{L}}$ is evaluated against the OIA by means of an ROC Plot (see Sect. 2.3).

The expected error of $P_{\mathrm{RZ}}$ is explored by comparing the empirical values of $P_{\mathrm{RzO}}$ 20 obtained for each subset and each zone size with the results of Eq. (2) (see Fig. 3d). It is expressed as a third-order polynomial regression function of the standard deviation of $P_{\mathrm{RZ}}$ :

$$
\sigma_{\mathrm{PRZ}}=b_{1}+b_{2} \log _{10} Z+b_{3}\left(\log _{10} Z\right)^{2}+b_{4}\left(\log _{10} Z\right)^{3}
$$

\section{NHESSD}

3, 5677-5715, 2015

Integrated statistical modelling of spatial landslide probability

M. Mergili and H.-J. Chu

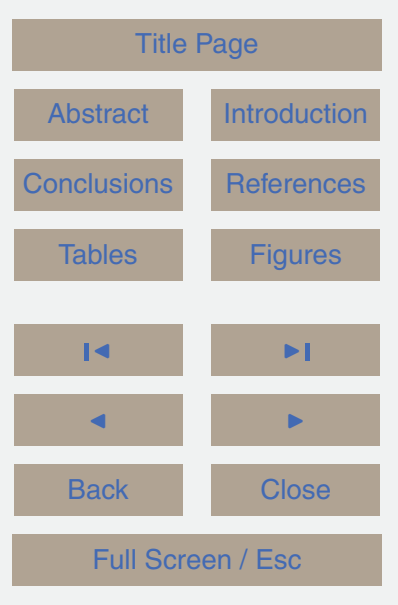

Printer-friendly Version

Interactive Discussion 
where $\sigma_{\mathrm{PRZ}}$ is the standard deviation of $P_{\mathrm{RZ}}$ and $b_{1}-b_{4}$ are the regression coefficients. The standard deviation of $P_{\mathrm{L}}, \sigma_{\mathrm{PL}}$, is derived as

$\sigma_{\mathrm{PL}}=\sigma_{\mathrm{PRZ}} \cdot P_{1}$

Equation (7) only applies to those pixels where $P_{\mathrm{Rz}} \cdot P_{1} \geq P_{\mathrm{R}}$.

5 We note that the described procedure is supposed to yield smoothed results due to averaging effects: (i) Eq. (5) builds on the simplification of a uniformly distributed release probability over the possible release zone. (ii) As highlighted in Sect. 2.5, $P_{1}$ represents the average of $P_{\mathrm{IR}}$ of all mass points impacting a pixel. This type of averaging is necessary to ensure a consistent combination of $P_{\mathrm{RZ}}$ and $P_{\mathrm{l}}$.

\section{Test area and parameterization}

\subsection{The Kao Ping test area}

In the period from 7 to 9 August 2009, Typhoon Morakot triggered a high number of landslides in Taiwan. According to Lin et al. (2011), more than 22000 landslides were recorded in Southern Taiwan. One of the hot spots was the Kao Ping Watershed

(Wu et al., 2011), where extremely heavy rainfall (more than $2000 \mathrm{~mm}$ in a period of $90 \mathrm{~h}$ ) caused an enormous amount of mass wasting and triggered a catastrophic landslide in the Hsiaolin Village (Kuo et al., 2013).

We consider a $637 \mathrm{~km}^{2}$ subset of the Kao Ping Watershed for computing the integrated spatial landslide probability $P_{\mathrm{L}}$ (Fig. 6). 1399 landslides triggered by the Typhoon Morakot are mapped in the shale, sandstone and colluvium slopes of the area. A stereo-photogrammetrically generated $10 \mathrm{~m}$ DEM is used along with a landslide inventory derived from FORMOSAT-2 scenes recorded before and after the event. The landslide inventory delineates the OIA without differentiating between ORA and ODA, and without providing direct information on landslide volumes. Overlapping landslide polygons are aggregated to one polygon for the purpose of the statistical analyses.

\section{NHESSD}

3, 5677-5715, 2015

Integrated statistical modelling of spatial landslide probability

M. Mergili and H.-J. Chu

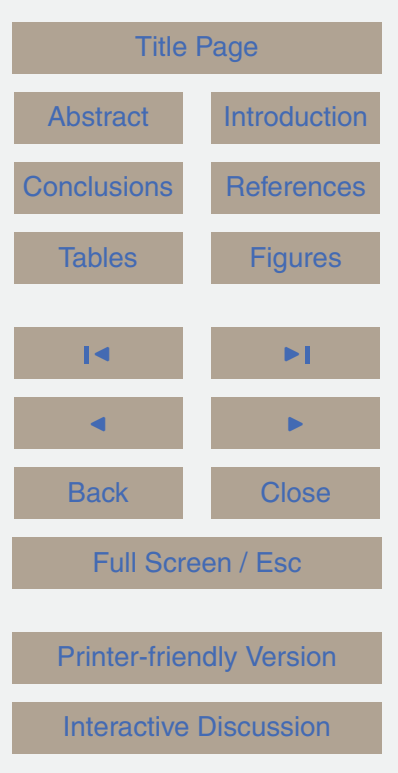

Interactive Discussion 


\subsection{Model parameterization}

The model tests are summarized in Table 2. The Kao Ping study area is divided into four subsets (A-D in Fig. 6) to separate between MDA and MEA. In each of the tests, three subsets are used as MDA and one subset is used as MEA. The division lines

5 between the subsets follow catchment boundaries in order to ensure that all landslides are clearly assigned to one of the four subsets and no landslide may impact more than one subset. All tests are run at a pixel size of $20 \mathrm{~m}$.

We use values of $r_{\mathrm{R}}=0.75$ and $r_{\mathrm{D}}=0.25$ (see Sect. 2.2). Preliminary tests have shown that the following two parameters are suitable as predictors for computing $P_{\mathrm{R}}$ : (i) local slope (five classes); and (ii) aspect (2 classes). For reasons of the regional geology, NE-E-SE-S-SW exposed slopes are more affected by landslides than WNW-N exposed slopes. Both predictors are derived from a modified version of the DEM: noise reduction is applied to the DEM through a low pass filter building on the mean of all values within in a radius of $50 \mathrm{~m}$.

15 For back-calculating $\omega_{\mathrm{O}}$ and for evaluating $P_{1}^{*}$ we start a set of $10^{3}$ random walks from each pixel in the ORA of the MDA and the MEA, respectively. For computing $P_{\mathrm{L}}$ we start a set of $10^{2}$ random walks from each pixel in the MEA. We use Gaussian distributions to generate the CDFs. The input parameters governing the routing procedure in r.randomwalk are chosen in accordance with the suggestions provided by Mergili et al. (2015).

Preliminary tests have further indicated that the largest, deep-seated landslides in the test area are poorly predicted by the statistical model applied. We hypothesize that landsides of this type are governed by other factors than those which can be derived directly from the DEM or other surface data. The analyses are therefore repeated excluding all landslides with a total size of the OIA $\geq 1 \mathrm{~km}^{2}$. All pixels within the OIA of those landslides are set to no data (Tests 2A-D in Table 2).

We further run the model with a spatially constant value of $P_{\mathrm{R}}$ (identical to the observed density of ORA in the MDA) in order to quantify the component of $P_{\mathrm{L}}$ (and of the

\section{NHESSD}

3, 5677-5715, 2015

Integrated statistical modelling of spatial landslide probability

M. Mergili and H.-J. Chu

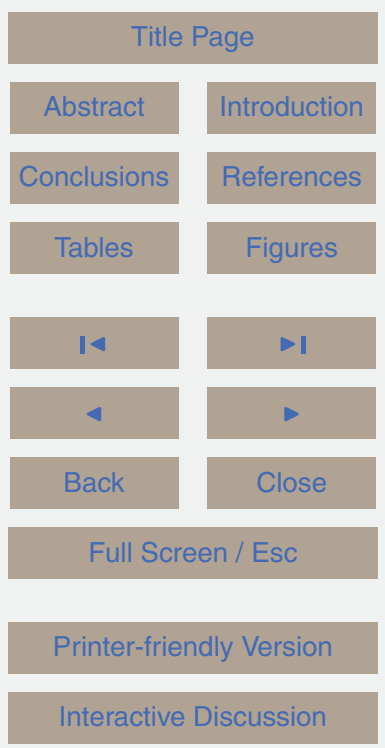


model performance) associated to the zone size used for computing $P_{\mathrm{Rz}}$ (see Sect. 2.6; Tests 3A-D in Table 2).

The model results are evaluated against the observed landslides at two spatial levels using ROC Plots:

- The pixel level. $P_{\mathrm{R}}$ is evaluated against the ORA, $P_{1}^{*}$ is evaluated against the ODA, and $P_{\mathrm{L}}$ is evaluated against the OIA.

- The level of slope units. The slope units are derived using the GRASS GIS module r.watershed (parameter half_basin), with a minimum area of one slope unit of $10^{4} \mathrm{~m}^{2}$. Each slope unit with at least one OP pixel is considered OP. The average and zonal values of $P_{\mathrm{R}}$ and $P_{\mathrm{L}}$ as well as the slope unit size are tested against the corresponding aggregated inventories.

\section{Results}

\subsection{Spatial patterns of landslide probability}

Figure 7 illustrates the result maps for test $1 \mathrm{C}$. For reasons of clarity, we show only 15 a subset of the test area (see Fig. 6). However, the general patterns of the results are well represented in this area and are also valid for the other tests. Figure $7 a$ shows the result of the inventory subsetting, the spatial variation of $P_{\mathrm{R}}$ is displayed in Fig. $7 \mathrm{~b}$. Whilst the patterns of $P_{1}^{*}$ related to the observed landslide release pixels (see Fig. $7 \mathrm{c}$ ) clearly reflect the decreasing probabilities in downslope direction, the values of $P_{1}$ related to all possible release pixels (see Fig. 7c) are high where large contiguous steep slopes are present i.e. where the average slope angles are high. The probability density function and the CDF of $\omega_{\mathrm{OT}}$ computed for the relevant MDA (including the zones A, B and D; see Fig. 6) are shown in Fig. 8a. According to the Figs. 4 and $8 \mathrm{a}, P_{1}^{*}=1$ for those areas where $\omega \geq$ the maximum of $\omega_{\mathrm{OT}}$. For $P_{\mathrm{l}}$, this is only true where $P_{\mathrm{IR}}=1$ for

\section{NHESSD}

3, 5677-5715, 2015

Integrated statistical modelling of spatial landslide probability

M. Mergili and H.-J. Chu

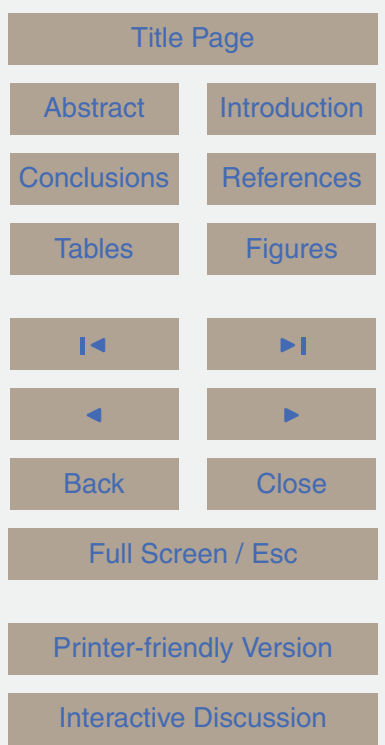


all mass points possibly impacting the considered pixel as $P_{1}$ represents the average of all relevant values of $P_{\mathrm{IR}}$ (see Fig. 5)

The largest values of $Z$ are displayed in those areas with large catchments i.e. in the valleys (see Fig. 7e). Whilst the maxima exceed $10 \mathrm{~km}^{2}$ in zone $\mathrm{C}$, the median of $Z$ for 5 all pixels in zone $C$ is $0.043 \mathrm{~km}^{2}$. The zonal release probability (see Fig. $7 f$ ) strongly reflects the patterns of $Z$, clearly dominating over the influence of $P_{\mathrm{R}}$ (see Figs. 3 and $7 \mathrm{~b}$ ). This phenomenon is explained by the limited spatial variation of $P_{\mathrm{R}}$ (see Fig. 7b) and the resulting dominance of the zone size reflected in $P_{\mathrm{Rz}}$. Figure $9 \mathrm{a}$ illustrates the dependency of the observed zonal release probability $P_{\text {RzO }}$ from the zone size (see 10 Fig. 3).

Note that high values of $P_{\mathrm{Rz}}$ are not associated to those areas with high release probabilities, but to the source areas of the random walks determining $P_{1}$ of the corresponding pixel (see Fig. 5). However, $P_{1}$ is usually low in those areas with very high values of $P_{\mathrm{RZ}}$ as they are located in the valleys at some distance from the steep slopes. 15 Therefore, the integrated spatial landslide probability $P_{\mathrm{L}}$ reaches its maxima on the lower slopes and in narrow gorges, where both $P_{\mathrm{Rz}}$ and $P_{\mathrm{l}}$ are relatively high (see Fig. $7 \mathrm{~g}$ ). The standard deviation shown in Fig. $7 \mathrm{~h}$ is derived from the standard deviation function of Fig. 9b (see Eqs. 6 and 7). $\sigma_{\mathrm{PRZ}}$ remains at a moderate level and is highest in those areas where also $P_{\mathrm{RZ}}$ is high.

20 Figure 10 shows the distribution of $P_{\mathrm{L}}$ for the entire test area. The maps for the tests $1 A-1 D$ - each of them covering the corresponding MEA - are combined into one map.

\subsection{Pixel-based evaluation against observed landslides}

Considering all observed landslides (tests $1 \mathrm{~A}-\mathrm{D}$ ), $7.5 \%$ of the entire test area are classified as OIA (i.e. the observed integrated spatial landslide probability). The average 25 value of $P_{\mathrm{L}}=9.3 \%$, meaning that we arrive at a reasonable estimate of the integrated spatial landslide probability, even though we overestimate $P_{\mathrm{L}}$. The same is true for the landslide release areas, where $1.4 \%$ of the test area are classified as ORA, with a similar average value of $P_{\mathrm{R}}$. Whilst the excellent correspondence of observed and modelled

\section{NHESSD}

3, 5677-5715, 2015

Integrated statistical modelling of spatial landslide probability

M. Mergili and H.-J. Chu

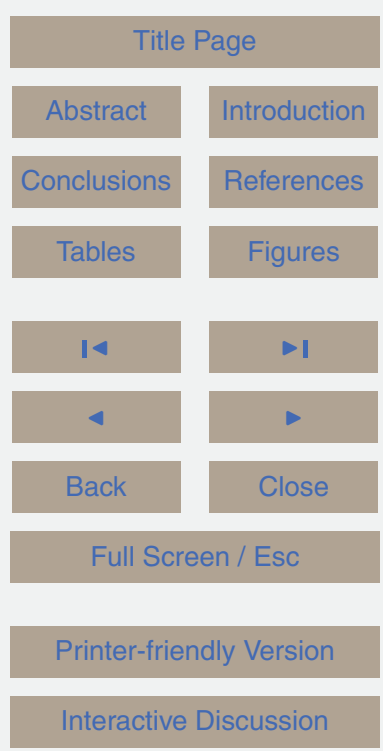


release probabilities is forced by the type of statistical approach employed, the still reasonable correspondence with regard to $P_{\mathrm{R}}$ indicates a certain validity of the suggested workflow. The key parameters characterizing the outcomes of each test (see Table 2) are summarized in Table 3. Observed and computed percentages are lower for the 5 tests $2 \mathrm{~A}-\mathrm{D}$ as some landslide areas are removed from the analysis.

The ROC Plots for model evaluation are compiled in Fig. 11. $P_{\mathrm{R}}$ is evaluated against the ORA, $P_{1}$ is evaluated against the ODA and $P_{\mathrm{L}}$ is evaluated against the OIA. Only the MEA is taken into account. Considering the tests $1 A-D$, the predictors slope and aspect only explain part of the spatial variation of $P_{\mathrm{R}}$, indicated by moderate levels of $10 \mathrm{AUC}_{\mathrm{ROC}}(0.569-0.661)$. The prediction level of test $1 \mathrm{D}$ even indicates model failure (see Fig. 11a). In contrast, the spatial variation of the observed deposition areas is comparatively well predicted by the modelled values of $P_{1}^{*}\left(0.724 \leq \mathrm{AUC}_{\mathrm{ROC}} \leq 0.913\right.$; see Fig. 11b). This observation is not surprising as the possible path of movement is usually reasonably well constrained, and most mass points necessarily touch the 15 observed impact areas whilst those pixels on slopes without observed landslides yield a large amount of "cheap" TN pixels (see Fig. 7c). Whilst $P_{1}$ derived by the routing of all possible release pixels (see Fig. 7d) is of theoretical nature and would be less useful to evaluate, $P_{\mathrm{L}}$ again displays a moderate prediction level $\left(0.605 \leq \mathrm{AUC}_{\mathrm{ROC}} \leq 0.685\right.$; see Fig. 11b) which is, however, better than $P_{\mathrm{R}}$. Considering the ROC Plots for $P_{\mathrm{R}}$ and $P_{1}^{*}$ indicates that the false predictions are a consequence of the uncertain release probability rather than of deficiencies in the routing procedure.

Removing the largest landslides (OIA $\geq 1 \mathrm{~km}^{2}$ ) from the data (Tests $\left.2 A-D\right)$ does not significantly change the general prediction quality with regard to $P_{\mathrm{R}}$ (see Fig. 11d).

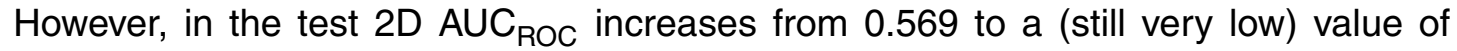
0.598, indicating that the large Hsiaolin Landslide located in zone D (see Fig. 6 ) is very poorly explained by the predictors used. The influence of removing large landslides (all of which are located in the zones $C$ and $D$ ) on the model performance in terms of $P_{1}^{*}$ is more obvious than in the case of $P_{\mathrm{R}}$ (see Fig. 11e). The tests $2 \mathrm{C}$ and $2 \mathrm{D}$ display a significantly enhanced performance, compared to the tests $1 \mathrm{C}$ and $1 \mathrm{D}(0.784$ to 0.863
NHESSD

3, 5677-5715, 2015

Integrated statistical modelling of spatial landslide probability

M. Mergili and H.-J. Chu

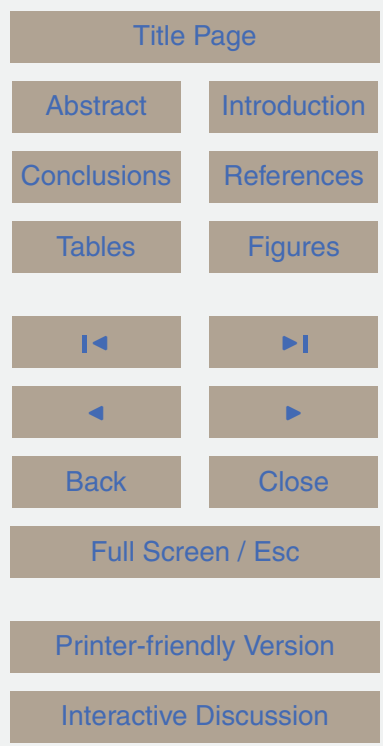


and 0.724 to 0.900 , respectively). This phenomenon is again a consequence of the particular settings associated to the large landslides (especially the Hsiaolin Landslide, the deposition area of which is very poorly predicted) yielding a large number of false negative pixels in the observed deposit. Coming back to Fig. 8b, the tests $1 \mathrm{~A}-\mathrm{D}$ yield 5 lower peaks of the probability density and a shift of the curves towards lower values of $\omega_{\mathrm{OT}}$, compared to the tests 2A-D (see Table 3 ). Those lower values of $\omega_{\mathrm{OT}}$ are associated to the large landslides excluded in the tests $2 A-D$. Consequently, $\omega_{T}$ is underestimated - and therefore, the impact area is overestimated - for the majority of the observed landslides in the tests $1 \mathrm{~A}-\mathrm{D}$. However, the shift in the model performance 10 is related to the poor prediction of the large deposit of the Hsiaolin Landslide rather than to the changes in the CDF.

In accordance with the patterns observed with regard to $P_{1}, \mathrm{AUC}_{\mathrm{ROC}}$ increases for the tests $2 \mathrm{C}$ and $\mathrm{D}$, compared to $1 \mathrm{C}$ and $\mathrm{D}$ (see Fig. 11f). In contrast, $\mathrm{AUC}_{\mathrm{ROC}}$ for $P_{\mathrm{L}}$ derived with the tests $2 A$ and $B$ decreases slightly, compared to the values obtained with the results for $1 \mathrm{~A}$ and $\mathrm{B}$. Figure $11 \mathrm{~g}$ illustrates the ROC Curves yielded for $P_{\mathrm{L}}$, assuming a constant spatial pattern of $P_{\mathrm{R}}$ (i.e. the fraction of observed landslide pixels in the MEA for each test 3A-D). The values of $A U C_{R O C}$ are almost similar to those yielded with the tests $1 A-D$ (see Fig. 11c). This observation indicates that the spatial differentiation of $P_{\mathrm{R}}$ is almost completely covered by the patterns of $P_{1}$ and $Z$ (see 20 Fig. 7).

\subsection{Evaluation against observed landslides on the basis of slope units}

The ROC Plots shown in the Fig. $11 \mathrm{~h}-\mathrm{I}$ relate the modelled distribution of $P_{\mathrm{R}}$ and $P_{\mathrm{L}}$ to the distribution of OP and ON slope units of the entire test area (in each case, the combination of the results of the tests $A-D$ ). All slope units with at least one OP pixel are considered OP, the ROC Curves are weighted for the slope unit size. The $A_{U C} C_{R O C}$ values derived for the average values of $P_{\mathrm{R}}$ for each slope unit evaluated against the aggregated ORA are significantly higher than the $A U C_{R O C}$ values derived at the pixel level ( 0.695 for the tests $1 A-D$ and 0.723 for the tests $2 A-D$; see Fig. $11 \mathrm{~h}$ and $\mathrm{j}$ ).

\section{2}

NHESSD

3, 5677-5715, 2015

Integrated statistical modelling of spatial landslide probability

M. Mergili and H.-J. Chu

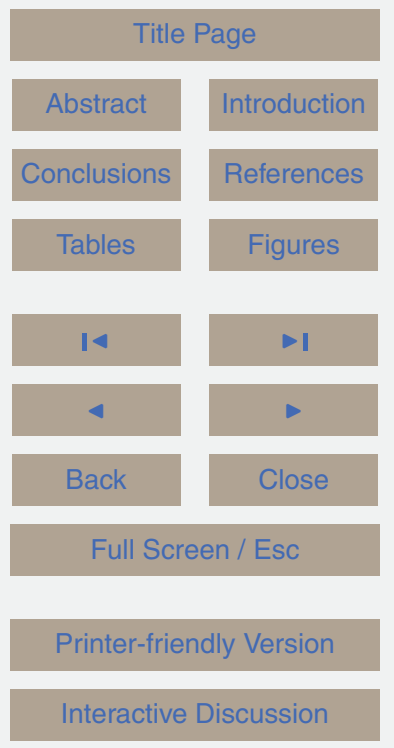


AUC $_{\text {ROC }}$ further increases to 0.787 and 0.766 , respectively, when the zonal values of $P_{\mathrm{R}}$ for the slope units are considered. This would be the correct way. However, these zonal probabilities are extremely strongly correlated to the size of the associated slope unit (this phenomenon is already indicated by Fig. 9), so that validating the zone size 5 against the ORA results in ROC Curves almost identical with those derived for the zonal probabilities. This means that, despite the high values of $A \cup C_{R O C}$, the zonal values of $P_{\mathrm{R}}$ for the slope units have no predictive power in terms of differentiating between areas of varying environmental or topographic conditions. The high prediction quality just relies on the fact that larger slope units are more likely to contain OP pixels 10 (see Sect. 2.4). This phenomenon was already indirectly shown by the comparison of the Fig. $11 \mathrm{c}$ and $\mathrm{g}$.

Slope units are not the suitable level to spatially aggregate $P_{\mathrm{L}}$ (see Fig. 11i, $\mathrm{k}$ and I). The average of $P_{\mathrm{L}}$ for each slope unit evaluated against the aggregated OIA indicates random predictions for all the sets of tests $\left(\mathrm{AUC}_{\mathrm{ROC}}=0.494-0.502\right)$. As for $P_{\mathrm{R}}$, AUC $_{\mathrm{ROC}}$ values $(0.771-0.779)$ in all tests. This implies limitations analogous to those described for $P_{\mathrm{R}}$.

\section{Discussion}

We have introduced a novel methodology to compute the spatial probability of an arbi20 trary raster pixel - or any other type of unit - to be affected by a landslide. Our approch considers both landslide release and propagation. It further introduces the concept of the zonal release probability for correcting (i) the release probability relevant for a certain impact pixel for the size of the possible release area, or (ii) any type of probability for a certain level of spatial aggregation.

25 The model results were evaluated at the pixel and slope unit levels. Slope units have been used earlier for discretizing and evaluating landslide release susceptibility maps (e.g. Rossi et al., 2010; Jia et al., 2012). Marchesini et al. (2015) have shown
NHESSD

$3,5677-5715,2015$

Integrated statistical modelling of spatial landslide probability

M. Mergili and H.-J. Chu

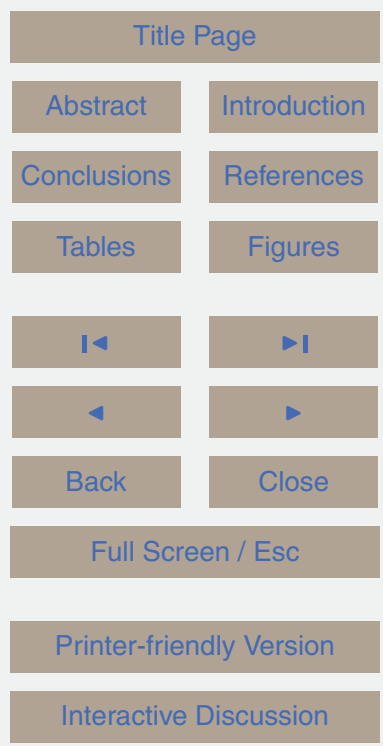


that a physically-based landslide susceptibility model performs better when evaluated at the level of slope units instead of pixels. In the present study, this phenomenon is confirmed for $P_{\mathrm{R}}$. It is also shown that slope units are unsuitable to discretize $P_{\mathrm{L}}$. The ORAs and the associated areas with high $P_{\mathrm{R}}$ are generally well confined to slope units 5 as they usually coincide with more or less steep slopes. In contrast, many OIAs touch more than one slope unit by crossing major drainage lines. As a consequence, almost the entire study area is considered OP with regard to the OIA, hampering a meaningful evaluation. In fact, it is generally questionable to evaluate average probabilities against binary observations at the level of slope units of varying sizes. Large slope units are 10 much more likely to contain landslide pixels than small slope units, so that the zonal probabilities introduced in the present work would be the appropriate criterion for evaluation. However, we have shown that the zonal probabilities strongly reflect the size of the associated slope units. Consequently, zonal probabilities are unsuitable to explain spatial patterns at the level of slope units or other predefined entities. In contrast, $P_{\mathrm{RZ}}$ 15 is highly useful to compute $P_{\mathrm{L}}$ at the pixel level where the zone sizes are not defined a priori, but computed separately for each pixel. Also here, the result depends on $P_{\mathrm{RZ}}$ (indirectly, the zone size $Z$ ) and $P_{\mathrm{l}}$ rather than on the pixel-based values of $P_{\mathrm{R}}$. Further, high values of $P_{\mathrm{R}}$ associated to single pixels or small groups of pixels are not reflected in $P_{\mathrm{L}}$ due to the smoothing immanent to the zonal probability concept. Averaging of $P_{\mathrm{l}}$ may induce a similar effect.

Whilst traditional statistically-based landslide susceptibility studies (e.g. Carrara et al., 1991; Baeza and Corominas, 2001; Dai et al., 2001; Lee and Min, 2001; Saha et al., 2005; Guzzetti, 2006; Komac, 2006; Lee and Sambath, 2006; Lee and Pradhan, 2007; Yalcin, 2008; Yilmaz, 2009; Nandi and Shakoor, 2010; Yalcin et al., 2011; Petschko et al., 2014) are useful to identify likely release areas at the pixel level, they appear to play a limited role when (i) considering integrated landslide probability; or (ii) aggregating the pixel-based results to larger spatial units. However, the strong correlation between zone size and the zonal value of $P_{\mathrm{R}}-$ and, consequently, the nonexistent reflection of $P_{\mathrm{R}}$ in $P_{\mathrm{L}}$ - is partly related to the moderate level at which the
NHESSD

3, 5677-5715, 2015

Integrated statistical modelling of spatial landslide probability

M. Mergili and H.-J. Chu

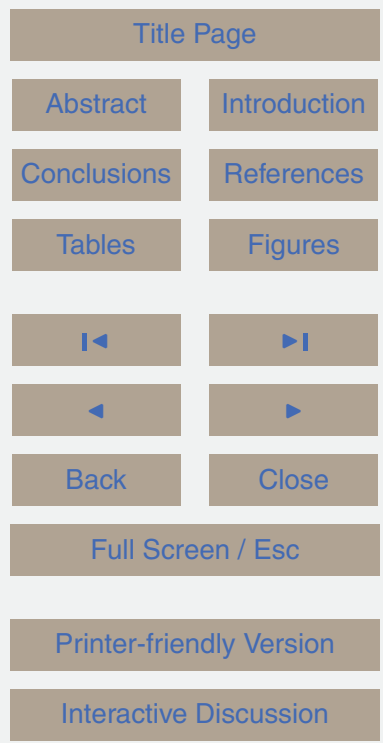


predictors used explain the spatial distribution of observed landslides. This low model performance is not surprising as we consider only one single meteorological event, expected to produce landslides at a certain randomness. The parameters governing landslide occurrence are partly stochastically distributed, particularly at fine scales 5 (e.g. Seyfried and Wilcox, 1995). Areas with high values of $P_{\mathrm{R}}$ are expected to produce landslides during future events, even if they were not affected by the Typhoon Morakot. In fact, those false positive pixels represent the most interesting areas in terms of future predictions as they tell us where landslides have not occurred, but are likely to occur in the future (Mergili et al., 2014a). This statement is equally valid in the context of $P_{\mathrm{L}}$.

10 The proposed approach is considered particularly useful for situations where landslides are highly mobile e.g. where they convert into debris flows. It has to be used with care where landslides are not mobile. In these cases, the CDF of the angle of reach would reflect the length distribution of the ORAs rather than the mobility of the landslides. In general, we note that the angles of reach used in the present study rely 15 on another concept than those included in published relationships (e.g. Scheidegger, 1973; Zimmermann et al., 1997; Rickenmann, 1999; Corominas et al., 2003; Noetzli et al., 2006): whilst these and other authors refer to the angle between the highest and the terminal point of the landslide, we consider the angles between any release pixel of an observed or hypothetic landslide and its terminal point. This is necessary to combine $P_{1}$ with $P_{\mathrm{RZ}}$, the latter referring to any arbitrary pixel possibly involved in a future landslide. Further, it is not possible to make $P_{1}$ dependent on landslide volumes as it was done, e.g. by Scheidegger (1973), Rickenmann (1999) or Noetzli et al. (2006). Such approaches are useful for single events with known volumes. However, as the volumes of possible future landslides are not a priori known at the scale relevant for the present study, we rely on the plain CDF.

The exclusion of large landslides improves the model performance. Particularly the well-investigated Hsiaolin Landslide (Kuo et al., 2013) is poorly predicted by the suggested approach with the parameters applied. We hypothesize that such events are sometimes characterized by very particular geotechnical and geological settings which
NHESSD

3, 5677-5715, 2015

Integrated statistical modelling of spatial landslide probability

M. Mergili and H.-J. Chu

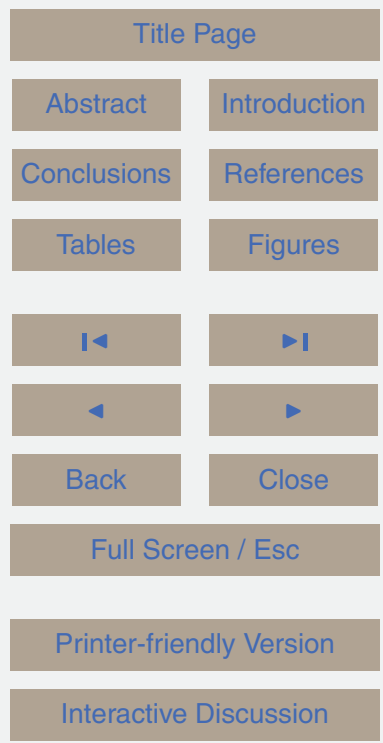


cannot necessarily be deduced from a DEM or remotely sensed data only. Instead, understanding, modelling and predicting those events relies on detailed on-site investigations and more advanced physically-based models.

Whilst it was out of scope of the present study to extensively evaluate the sensitivity of the model results to the various parameters used, such an evaluation has to be the subject of future studies, including (i) the predictors; (ii) the type of statistical method for computing $P_{\mathrm{R}}$; (iii) the number of random walks and the parameters constraining the random walks (see Mergili et al., 2015); (iv) the pixel size; and (v) the spatial units considered. Particularly with regard to $P_{\mathrm{R}}$, alternatives to the pixel-based approach have to be tested not only for evaluation, but also for establishing the statistical rules. We further note that all inventory subsets and probabilities (ORA, ODA and $P_{\mathrm{R}}$ in particular, to a much lesser extent also the other probabilities) are influenced by the choice of $r_{\mathrm{R}}$ and $r_{\mathrm{D}}$ (see Sect. 2.2). Keeping in mind all the possible influences of varying parameter combinations, we have to emphasize that the probabilities computed in the present work have to be understood as relative probabilities in the context of the particular settings applied to all tests.

\section{Conclusions}

We have presented an innovative approach for integrated statistical modelling of the spatial probability of landslides at catchment or broader scales. For this purpose we have combined the tools r.landslides.statistics and r.randomwalk. The release probability was computed using a simple overlay of the landslide inventory with a set of predictor layers whilst landslide propagation - i.e. the impact probability - was deduced from the cumulative probability of the angle of reach of the observed landslide pixels. The concept of zonal release probability was introduced, allowing to correct the release probability for the size of the release area possibly affecting a given pixel before combining the impact probability and the release probability.

\section{NHESSD}

3, 5677-5715, 2015

Integrated statistical modelling of spatial landslide probability

M. Mergili and H.-J. Chu

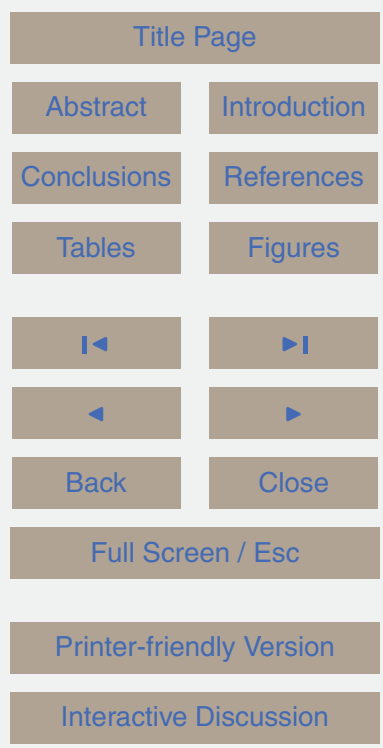


The result approximates the probability of a pixel to be affected by a landslide either through its release or through its propagation. Analyzing the outcomes of the procedure leads us to a set of key conclusions:

- The predictors used explain the observed landslide distribution only at a moderate performance level. This observation may be related to the fact that the landslides are attributed to one single meteorological event (the typhoon Morakot).

- The prediction quality does not decrease when using a constant release probability over the entire area. This indicates that the size of the possible release area is more important for the zonal release probability than the pixel-based release probability. This conclusion is supported by the outcome of the evaluation of the results on the basis of slope units.

- Even though this effect may be less pronounced for areas where the distribution of the release areas is well explained by the environmental layers, we conclude that the outcomes of traditional statistical landslide susceptibility analyses are less relevant for the integrated landslide probability and for higher levels of spatial aggregation.

- Removing the largest observed landslides from the analysis improves the prediction quality. We explain this phenomenon with particular geological settings not deducible from terrain data conditioning some of these events, and conclude that in-detail studies and physically-based models are needed in this context.

Confirming, refining and improving the results obtained will rely on thorough tests of parameter sensitivity.

Acknowledgements. The support of Massimiliano Alvioli, Matthias Benedikt, Yi-Chin Chen, Julia Krenn and Ivan Marchesini is acknowledged.

\section{NHESSD}

3, 5677-5715, 2015

Integrated statistical modelling of spatial landslide probability

M. Mergili and H.-J. Chu Title Page

Abstract Introduction Conclusions

Tables References Figures

14

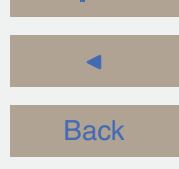
$\rightarrow 1$

Full Screen / Esc

Printer-friendly Version

Interactive Discussion 


\section{References}

Baeza, C. and Corominas, J.: Assessment of shallow landslide susceptibility by means of multivariate statistical techniques, Earth Surf. Proc. Land., 26, 1251-1263, 2001.

Brenning, A.: Spatial prediction models for landslide hazards: review, comparison and evaluation, Nat. Hazards Earth Syst. Sci., 5, 853-862, doi:10.5194/nhess-5-853-2005, 2005.

Carrara, A., Cardinali, M., Detti, R., Guzzetti, F., Pasqui, V., and Reichenbach, P.: GIS techniques and statistical models in evaluating landslide hazard, Earth Surf. Proc. Land., 16, 427-445, 1991.

Christen, M., Bartelt, P., and Kowalski, J.: Back calculation of the In den Arelen avalanche with RAMMS: interpretation of model results, Ann. Glaciol., 51, 161-168, 2010a.

Christen, M., Kowalski, J., and Bartelt, B.: RAMMS: numerical simulation of dense snow avalanches in three-dimensional terrain, Cold Reg. Sci. Technol., 63,1-14, 2010b.

Corominas, J., Copons, R., Vilaplana, J. M., Altamir, J., and Amigó, J.: Integrated Landslide Susceptibility Analysis and Hazard Assessment in the Principality of Andorra, Nat. Hazards,

15 30, 421-435, 2003.

Dai, F. C., Lee, C. F., and Zhang, X. H.: GIS-based geo-environmental evaluation for urban land-use planning: a case study, Eng. Geol., 61, 257-271, 2001.

Gamma, P.: Dfwalk - Murgang-Simulationsmodell zur Gefahrenzonierung, Geographica Bernensia, Bern, G66, 2000.

GRASS Development Team: Geographic Resources Analysis Support System (GRASS) Software, Version 7.0, Open Source Geospatial Foundation, available at: http://grass.osgeo.org, last access: 27 July 2015.

Gruber, F. E. and Mergili, M.: Regional-scale analysis of high-mountain multi-hazard and risk indicators in the Pamir (Tajikistan) with GRASS GIS, Nat. Hazards Earth Syst. Sci., 13, 27792796, doi:10.5194/nhess-13-2779-2013, 2013.

Guzzetti, F.: Landslide Hazard and Risk Assessment, PhD dissertation, University of Bonn, Bonn, 2006.

Heim, A.: Bergsturz und Menschenleben, Fretz und Wasmuth, Zürich, 1932.

Horton, P., Jaboyedoff, M., Rudaz, B., and Zimmermann, M.: Flow-R, a model for susceptibility mapping of debris flows and other gravitational hazards at a regional scale, Nat. Hazards Earth Syst. Sci., 13, 869-885, doi:10.5194/nhess-13-869-2013, 2013.
NHESSD

3, 5677-5715, 2015

Integrated statistical modelling of spatial landslide probability

M. Mergili and H.-J. Chu

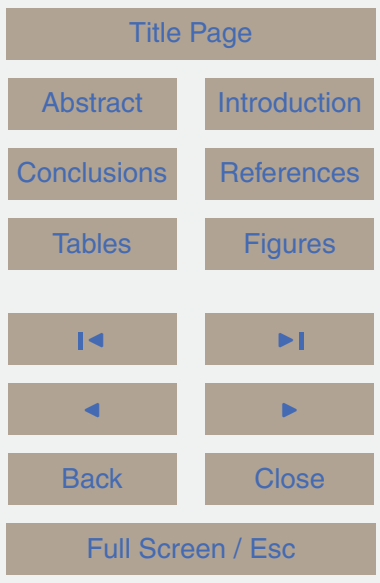

Printer-friendly Version

Interactive Discussion 
Komac, M.: A landslide susceptibility model using the analytical hierarchy process method and multivariate statistics in perialpine Slovenia, Geomorphology, 74, 17-28, 2006.

Kuo, Y. S., Tsai, Y. J., Chen, Y. S., Shieh, C. L., Miyamoto, K., and Itoh, T.: Movement of deepseated rainfall-induced landslide at Hsiaolin Village during Typhoon Morakot, Landslides, 10, 191-202, 2013.

Lee, S. and Min, K.: Statistical analysis of landslide susceptibility at Yongin, Korea, Environ. Geol., 40, 1095-1113, 2001.

Lee, S. and Pradhan, B.: Landslide hazard mapping at Selangor, Malaysia using frequency ratio and logistic regression models, Landslides, 4, 33-41, 2007.

10 Lee, S. and Sambath, T.: Landslide susceptibility mapping in the Damrei Romel area, Cambodia using frequency ratio and logistic regression models, Environ. Geol., 50, 847-855, 2006.

Lin, C. W., Chang, W. S., Liu, S. H., Tsai, T. T., Lee, S. P., Tsang, Y. C., Shieh, C. J., and Tseng, C. M.: Landslides triggered by the 7 August 2009 Typhoon Morakot in southern Taiwan, Eng. Geol., 123, 3-12, 2011.

Marchesini, I., Mergili, M., Schneider-Muntau, B., Alvioli, M., Rossi, M., and Guzzetti, F.: Physically-based landslide susceptibility modelling: geotechnical testing and model evaluation issues, Geophys. Res. Abstracts, 17, EGU205-3660, 2015.

Mergili, M., Fellin, W., Moreiras, S. M., and Stötter, J.: Simulation of debris flows in the Central Andes based on Open Source GIS: possibilities, limitations, and parameter sensitivity, Nat. Hazards, 61, 1051-1081, 2012.

Mergili, M., Marchesini, I., Rossi, M., Guzzetti, F., and Fellin, W.: Spatially distributed threedimensional slope stability modelling in a raster GIS, Geomorphology, 206, 178-195, 2014a.

Mergili, M., Marchesini, I., Alvioli, M., Metz, M., Schneider-Muntau, B., Rossi, M., and Guzzetti, F.: A strategy for GIS-based 3-D slope stability modelling over large areas, Geosci. Model Dev., 7, 2969-2982, doi:10.5194/gmd-7-2969-2014, 2014b.

Mergili, M., Krenn, J., and Chu, H.-J.: r.randomwalk v1.0, a multi-functional conceptual tool for mass movement routing, Geosci. Model Dev. Discuss., accepted, 2015.

Nandi, A. and Shakoor, A.: A GIS-based landslide susceptibility evaluation using bivariate and multivariate statistical analyses, Eng. Geol., 110, 11-20, 2010.

30 Neteler, M. and Mitasova, H.: Open Source GIS: a GRASS GIS Approach, Springer, New York, 2007.

Noetzli, J., Huggel, C., Hoelzle, M., and Haeberli, W.: GIS-based modelling of rock-ice avalanches from Alpine permafrost areas, Comput. Geosci., 10, 161-178, 2006.

\section{NHESSD}

3, 5677-5715, 2015

Integrated statistical modelling of spatial landslide probability

M. Mergili and H.-J. Chu

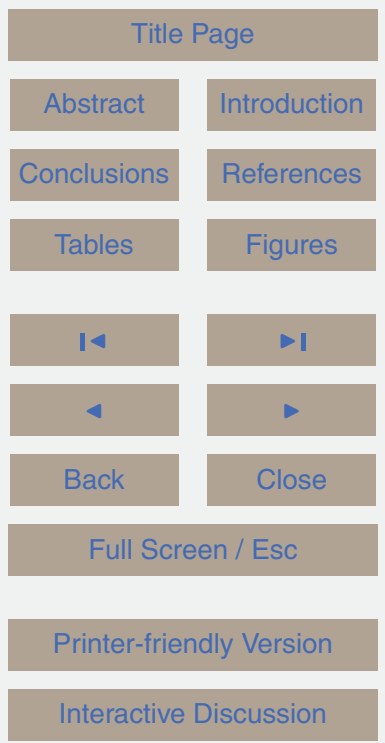


Perla, R., Cheng, T. T., and McClung, D. M.: A two-parameter model of snow avalanche motion, J. Glaciol., 26, 197-207, 1980.

Petschko, H., Brenning, A., Bell, R., Goetz, J., and Glade, T.: Assessing the quality of landslide susceptibility maps - case study Lower Austria, Nat. Hazards Earth Syst. Sci., 14, 95-118, doi:10.5194/nhess-14-95-2014, 2014.

R Core Team.: R: a Language and Environment for Statistical Computing, R Foundation for Statistical Computing, Vienna, Austria, available at: http://www.R-project.org, last access: 23 September 2015.

Rickenmann, D.: Empirical relationships for debris flows, Nat. Hazards, 19, 47-77, 1999.

10 Rossi, M., Guzzetti, F., Reichenbach, P., Mondini, A. C., and Peruccacci, S.: Optimal landslide susceptibility zonation based on multiple forecasts, Geomorphology, 114, 129-142, 2010.

Saha, A. K., Gupta, R. P., Sarkar, I., Arora, M. K., and Csaplovics, E.: An approach for GISbased statistical landslide susceptibility zonation - with a case study in the Himalayas, Landslides, 2, 61-69, 2005.

15 Scheidegger, A. E.: On the Prediction of the reach and velocity of catastrophic landslides, Rock Mech., 5, 231-236, 1973.

Seyfried, M. and Wilcox, B.: Scale and the nature of spatial variability: field examples having implications for hydrologic modeling, Water Resour. Res., 31, 173-184, 1995.

Van Westen, C. J., van Asch, T. W. J., and Soeters, R.: Landslide hazard and risk zonation: why 20 is it still so difficult?, B. Eng. Geol. Environ, 65, 176-184, 2005.

Voellmy, A.: Über die Zerstörungskraft von Lawinen, Schweiz. Bauzeitung, 73, 159-162, 212217, 246-249, 280-285, 1955.

Wichmann, V. and Becht, M.: Modelling of geomorphic processes in an alpine catchment, in: Proceedings of the 7th International Conference on GeoComputation, Southampton, 2003.

Wu, C. H., Chen, S. C., and Chou, H. T.: Geomorphologic characteristics of catastrophic landslides during typhoon Morakot in the Kaoping Watershed, Taiwan, Eng. Geol., 123, 13-21, 2011.

Yalcin, A.: GIS-based landslide susceptibility mapping using analytical hierarchy process and bivariate statistics in Ardesen (Turkey): comparisons of results and confirmations, Catena, 30 72, 1-12, 2008.

Yalcin, A., Reis, S., Aydinoglu, A. C., and Yomralioglu, T.: A GIS-based comparative study of frequency ratio, analytical hierarchy process, bivariate statistics and logistics regression methods for landslide susceptibility mapping in Trabzon, NE Turkey, Catena, 85, 274-287, 2011.

NHESSD

3, 5677-5715, 2015

Integrated statistical modelling of spatial landslide probability

M. Mergili and H.-J. Chu

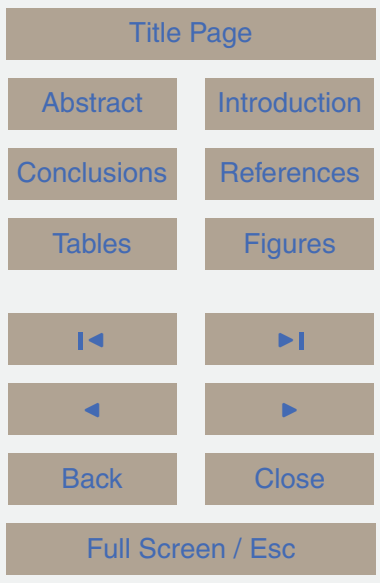

Printer-friendly Version

Interactive Discussion 
Yilmaz, I.: Landslide susceptibility mapping using frequency ratio, logistic regression, artificial neural networks and their comparison: a case study from Kat landslides (Tokat - Turkey), Comput. Geosci., 35, 1125-1138, 2009.

Zimmermann, M., Mani, P., and Gamma, P.: Murganggefahr und Klimaänderung - ein GIS basierter Ansatz, NFP 31 Schlussbericht, Hochschulverlag an der ETH, Zürich, 1997.

Integrated statistical modelling of spatial landslide probability

M. Mergili and H.-J. Chu

Title Page

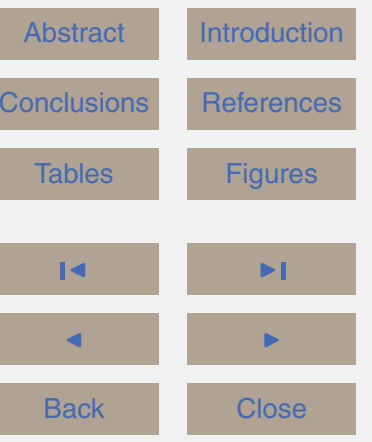

Full Screen / Esc

Printer-friendly Version

Interactive Discussion

(c) (i) 


\section{NHESSD}

3, 5677-5715, 2015

Table 1. Summary of the various probabilities as defined in the context of the present work.

\begin{tabular}{lll}
\hline Variable & Name & Description \\
\hline$P_{\mathrm{R}}$ & Release probability & $\begin{array}{l}\text { Spatial probability of a pixel to become a landslide } \\
\text { release pixel }\end{array}$ \\
\hline$P_{\mathrm{IR}}$ & Specific impact probability & $\begin{array}{l}\text { Spatial probability of a pixel to be impacted by the } \\
\text { propagation of a mass point starting from one defined } \\
\text { pixel. }\end{array}$ \\
\hline$P_{\mathrm{I}}^{*}$ & $\begin{array}{l}\text { Impact probability related to } \\
\text { observed release pixels }\end{array}$ & $\begin{array}{l}\text { Spatial probability of a pixel to be impacted by the } \\
\text { propagation of mass points starting from an arbitrary } \\
\text { number of observed landslide release pixels. In the case } \\
\text { of more than one mass point impacting a pixel, the } \\
\text { maximum of all values of } P_{\mathrm{IR}} \text { applies. }\end{array}$ \\
\hline$P_{\mathrm{I}}$ & $\begin{array}{l}\text { Impact probability related to } \\
\text { all pixels }\end{array}$ & $\begin{array}{l}\text { Spatial probability of a pixel to be impacted by the } \\
\text { propagation of mass points starting from all pixels in } \\
\text { a given area. In the case of more than one mass point } \\
\text { impacting a pixel, the average of all values of } P_{\mathrm{IR}} \text { applies. }\end{array}$ \\
\hline$P_{\mathrm{RZ}}$ & Zonal release probability & $\begin{array}{l}\text { Spatial probability that at least one landslide pixel exists } \\
\text { within the possible release zone relevant for the } \\
\text { considered pixel. }\end{array}$ \\
\hline$P_{\mathrm{L}}$ & $\begin{array}{l}\text { Integrated spatial landslide } \\
\text { probability }\end{array}$ & $\begin{array}{l}\text { Spatial probability that a pixel is affected by a landslide } \\
\text { either through release or through propagation. }\end{array}$ \\
\hline
\end{tabular}

Integrated statistical modelling of spatial landslide probability

M. Mergili and H.-J. Chu Title Page

\begin{tabular}{|c|c|}
\hline Abstract & Introduction \\
\hline Conclusions & References \\
\hline Tables & Figures \\
\hline I & \\
\hline 4 & $>$ । \\
\hline Back & Close \\
\hline Full Screen / Esc \\
\hline
\end{tabular}

Printer-friendly Version

Interactive Discussion 
Table 2. Summary of model tests. All tests build on the combination of the tools r.landslides.statistics and r.randomwalk. Refer to Fig. 6 for the subsets A-D used to define the MDA and the MEA.

\begin{tabular}{lllll}
\hline ID & Description & Components & MDA & MEA \\
\hline 1A & All landslides, & $P_{\mathrm{R}}, P_{\mathrm{l}}$, & B, C, D & ABCD \\
1B & all model & $P_{\mathrm{RZ}}, P_{\mathrm{L}}$ & A, C, D & \\
1C & components & & A, B, D & \\
1-D & & & A, B, C & \\
\hline 2A & Large & $P_{\mathrm{R}}, P_{\mathrm{l}}$, & B, C, D & ABCD \\
2B & landslides & $P_{\mathrm{RZ}}, P_{\mathrm{L}}$ & A, C, D & \\
2C & excluded & & A, B, D & \\
2-D & & & A, B, C & \\
\hline 3A & All landslides, & $P_{\mathrm{l}}, P_{\mathrm{RZ}}$, & B, C, D & ABCD \\
3B & constant $P_{\mathrm{R}}$ & $P_{\mathrm{L}}$ & A, C, D & \\
3C & & & A, B, D & \\
3-D & & & A, B, C & \\
\hline
\end{tabular}

\section{NHESSD}

3, 5677-5715, 2015

Integrated statistical modelling of spatial landslide probability

M. Mergili and H.-J. Chu Title Page

Abstract Introduction Conclusions References

Tables Figures

14

$\triangleleft$

Back

Close

Full Screen / Esc

Printer-friendly Version

Interactive Discussion 
Table 3. Key figures describing the results of the twelve tests introduced in Table 2. The IDs $1-3$ refer to the combined results from each set A-D. All values given in per cent are averages over the area indicated.

\begin{tabular}{llllllllll}
\hline ID & \multicolumn{3}{c}{ MDA $\left(\mathrm{km}^{2}\right)$} & \multicolumn{5}{c}{ MEA $\left(\mathrm{km}^{2}\right)$} \\
& $\begin{array}{l}\text { Size } \\
\left(\mathrm{km}^{2}\right)\end{array}$ & $\begin{array}{l}\text { ORA } \\
(\%)\end{array}$ & $\begin{array}{l}\text { OIA } \\
(\%)\end{array}$ & $\begin{array}{l}\text { Peak of } \\
\omega_{\text {OT }}\left(^{\circ}\right)\end{array}$ & $\begin{array}{l}\text { Size } \\
\left(\mathrm{km}^{2}\right)\end{array}$ & $\begin{array}{l}\text { ORA } \\
(\%)\end{array}$ & $\begin{array}{l}\text { OIA } \\
(\%)\end{array}$ & $\begin{array}{l}P_{\mathrm{R}} \\
(\%)\end{array}$ & $\begin{array}{l}P_{\mathrm{L}} \\
(\%)\end{array}$ \\
\hline 1A & 492.0 & 1.44 & 7.92 & 28.1 & 145.2 & 1.18 & 6.12 & 1.65 & 10.83 \\
1B & 506.9 & 1.49 & 8.21 & 28.1 & 130.3 & 0.96 & 4.80 & 1.62 & 10.73 \\
1C & 436.3 & 1.25 & 6.79 & 29.0 & 200.9 & 1.67 & 9.08 & 1.37 & 8.96 \\
1D & 476.4 & 1.33 & 7.01 & 29.4 & 160.8 & 1.54 & 9.01 & 1.23 & 7.06 \\
\hline 2A & 492.0 & 1.23 & 6.23 & 29.7 & 145.2 & 1.18 & 6.12 & 1.42 & 9.74 \\
2B & 506.9 & 1.29 & 6.57 & 29.8 & 130.3 & 0.96 & 4.80 & 1.41 & 9.52 \\
2C & 436.3 & 1.12 & 5.73 & 30.2 & 200.9 & 1.43 & 7.24 & 1.25 & 8.15 \\
2D & 476.4 & 1.23 & 6.22 & 30.5 & 160.8 & 1.20 & 6.14 & 1.15 & 6.14 \\
\hline 3A & 492.0 & 1.44 & 7.92 & 28.1 & 145.2 & 1.18 & 6.12 & 1.24 & 10.67 \\
3B & 506.9 & 1.49 & 8.21 & 28.1 & 130.3 & 0.96 & 4.80 & 1.00 & 10.48 \\
3C & 436.3 & 1.25 & 6.79 & 29.0 & 200.9 & 1.67 & 9.08 & 1.80 & 9.66 \\
3D & 476.4 & 1.33 & 7.01 & 29.4 & 160.8 & 1.54 & 9.01 & 1.66 & 7.18 \\
\hline 1 & & & & & $637.2^{*}$ & $1.38^{*}$ & $7.51^{*}$ & $1.45^{*}$ & $9.27^{*}$ \\
2 & & & & & $637.2^{*}$ & $1.22^{*}$ & $6.20^{*}$ & $1.30^{*}$ & $8.28^{*}$ \\
3 & & & & & $637.2^{*}$ & $1.38^{*}$ & $7.51^{*}$ & $1.48^{*}$ & $9.43^{*}$ \\
\hline
\end{tabular}

Values marked with an asterisk represent averages for the entire test area.
NHESSD

3, 5677-5715, 2015

Integrated statistical modelling of spatial landslide probability

M. Mergili and H.-J. Chu

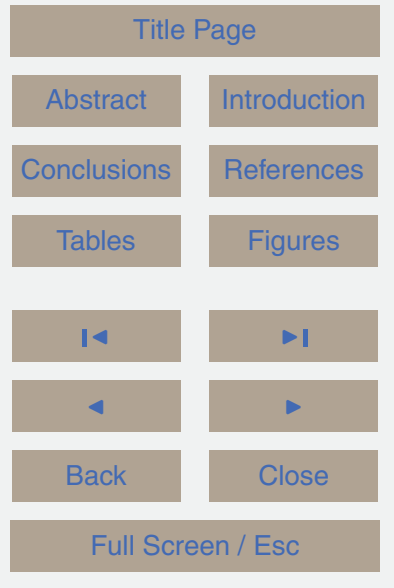

Printer-friendly Version

Interactive Discussion 


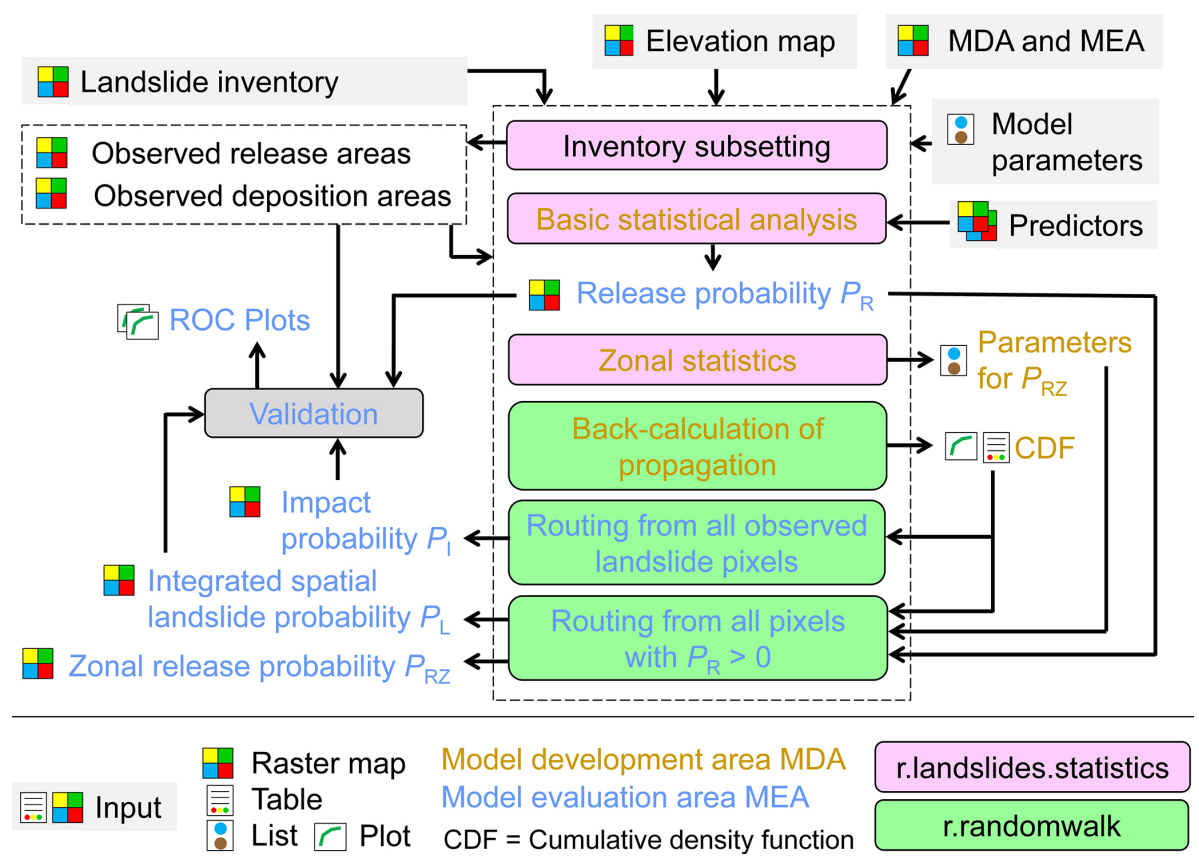

Figure 1. Simplified work flow of the integrated statistical analysis of spatial landslide probability.

\section{NHESSD}

3, 5677-5715, 2015

Integrated statistical modelling of spatial landslide probability

M. Mergili and H.-J. Chu

\section{Title Page}

\begin{tabular}{|c|c|}
\hline Abstract & Introduction \\
\hline Conclusions & References \\
\hline Tables & Figures \\
\hline 14 & \\
\hline 4 & \\
\hline Back & Close \\
\hline
\end{tabular}

Full Screen / Esc

Printer-friendly Version

Interactive Discussion 


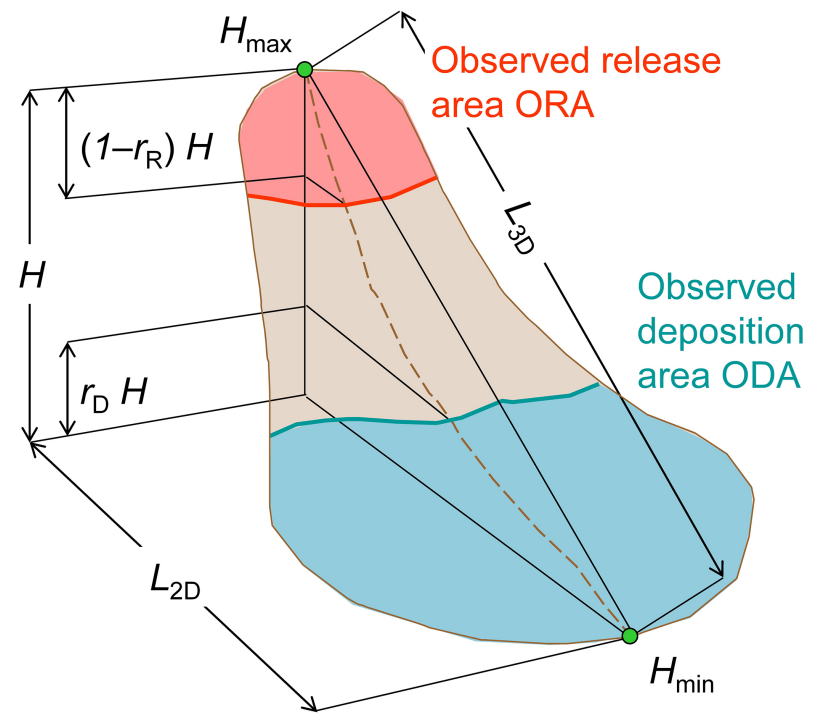

Integrated statistical modelling of spatial landslide probability

M. Mergili and H.-J. Chu

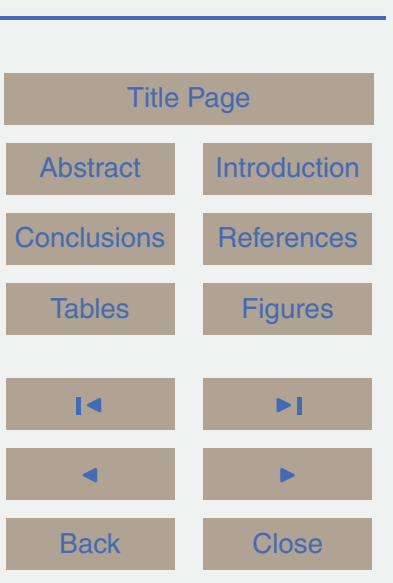

Figure 2. Landslide geometry and inventory subsetting. ORA and ODA are defined on the basis of $r_{\mathrm{R}}$ and $r_{\mathrm{D}}$.

Full Screen / Esc

Printer-friendly Version

Interactive Discussion 


\section{(a) Sampling, $\boldsymbol{P}_{\text {Rzo }}$}

$4 \times 1+4 \times 0 \rightarrow P_{\text {RZO }}=0.50$

$3 \times 1+1 \times 0 \rightarrow P_{\mathrm{PZO}}=0.75$

$2 \times 1+0 \times 0 \rightarrow P_{\mathrm{RZO}}=1.00$

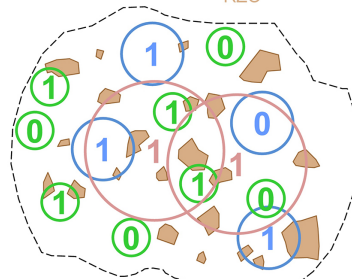

(c) Approximation of $P_{\mathrm{RZ}}$

Q

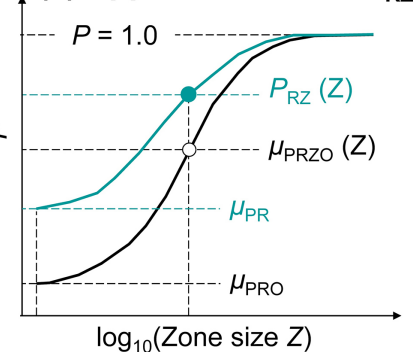

(b) Logistic regression

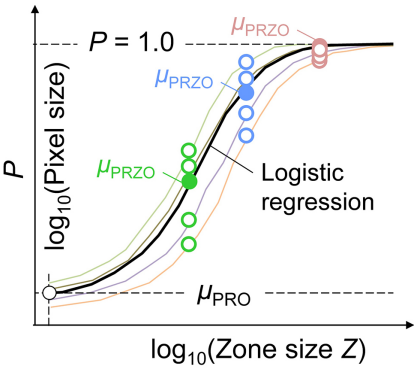

(d) Error of $P_{\mathrm{RZ}}$

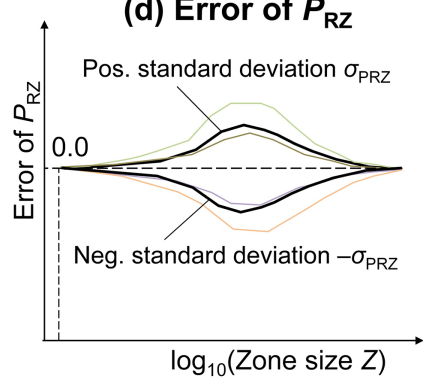

NHESSD

3, 5677-5715, 2015

Integrated statistical modelling of spatial landslide probability

M. Mergili and H.-J. Chu

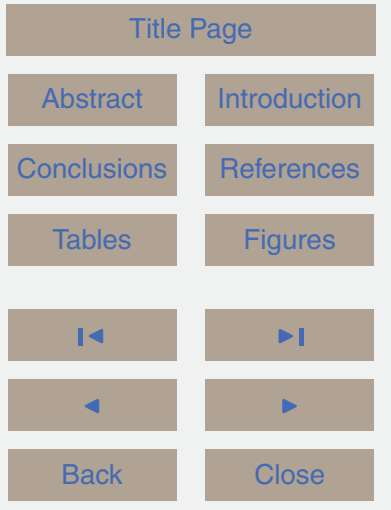

Full Screen / Esc

Printer-friendly Version

Interactive Discussion 
(a) Back-calculation of $\omega_{T}$

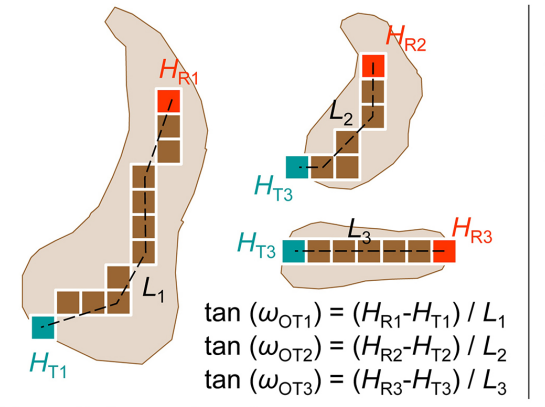

(c) $P_{1}$ for observed landslides

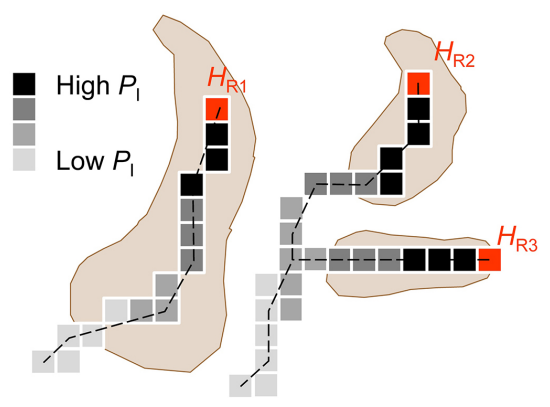

NHESSD

3, 5677-5715, 2015

Integrated statistical modelling of spatial landslide probability

M. Mergili and H.-J. Chu

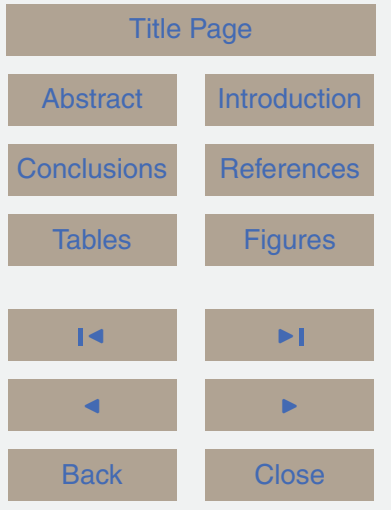

Full Screen / Esc

Printer-friendly Version

Interactive Discussion (a) here, only one random walk for one release pixel is shown whilst in reality, r.randomwalk starts sets of random walks from all release pixels of all observed landslides. Estimating $P_{1}$ for all release pixels in the test area works in a way analogous to (c). 


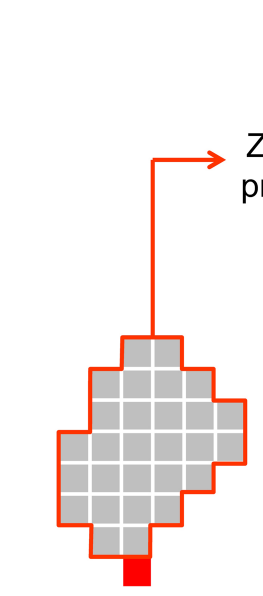

Area of possible release zone $Z$

Impact pixel
Fig. 2, Eq. 4<smiles>C1C[Al]C1</smiles>

Eq. 5

Zonal release probability $P_{\mathrm{RZ}}$

$\uparrow$

Mean of $P_{\mathrm{R}} \quad P_{\mathrm{I}}$ (Mean of $P_{\mathrm{IR}}$ )

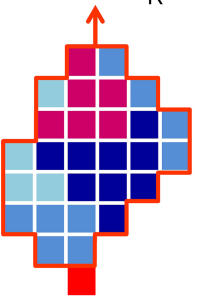

- $\square+$

Release

probability

$P_{\mathrm{R}}$

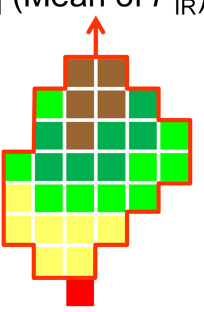

probability

$P_{\mathrm{IR}}$
Specific impact

Figure 5. Integrated spatial landslide probability $P_{\mathrm{L}}$ for a given impact pixel as a function of the release probability $P_{\mathrm{R}}$, the impact probability $P_{1}$ and the size of the possible release area $Z$. The average of $P_{\mathrm{R}}$ and the value of $Z$ associated to each impact pixel are used along with Eq. (4) to compute the zonal release probability $P_{\mathrm{RZ}}$ (see Fig. 3c). $P_{\mathrm{RZ}}$ and $P_{\mathrm{l}}$ are multiplied to compute $P_{\mathrm{L}}$ (see Eq. 5). Note that (i) for readability, the values of $P_{\mathrm{IR}}$ are shown for the associated release pixels even though they apply to the impact pixel; (ii) if $P_{\mathrm{R}}$ of the impact pixel $>P_{\mathrm{RZ}} \cdot P_{\mathrm{l}}, P_{\mathrm{L}}=P_{\mathrm{R}}$.

Integrated statistical modelling of spatial landslide probability

M. Mergili and H.-J. Chu

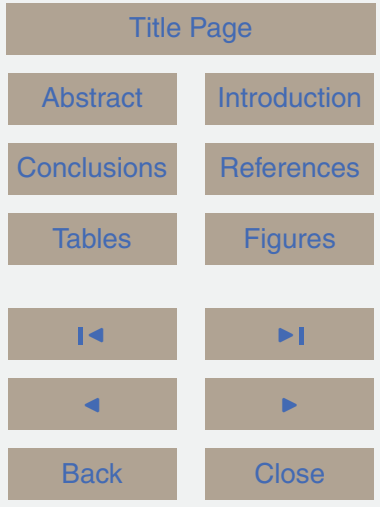

Full Screen / Esc

Printer-friendly Version

Interactive Discussion 


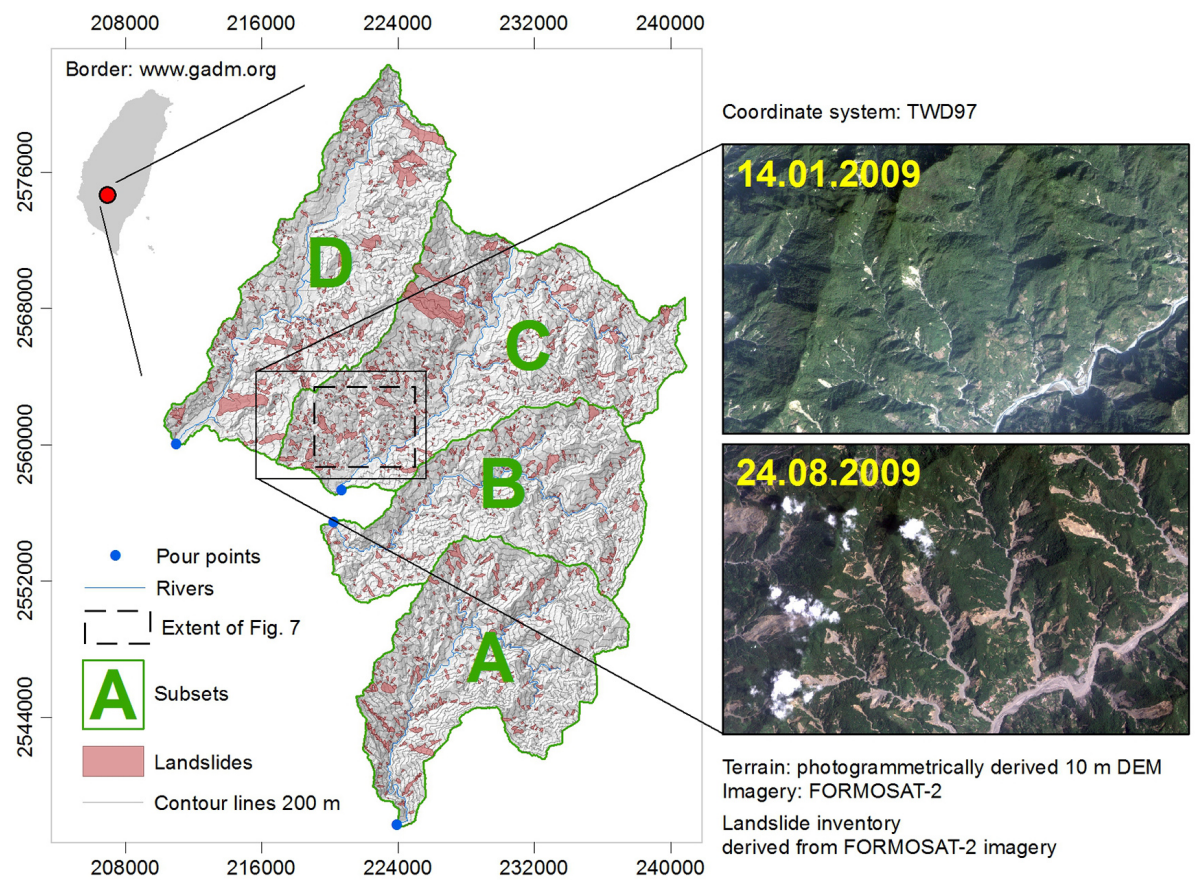

Figure 6. The test area in the Kao Ping Watershed in southern Taiwan. A-D refer to the subsets of the test area alternatively used as MDA and MEA (see Table 2). The comparison of pre- and post-event imagery for part of the test area illustrates the large number of landslides triggered by the typhoon Morakot.

\section{NHESSD}

3, 5677-5715, 2015

Integrated statistical modelling of spatial landslide probability

M. Mergili and H.-J. Chu

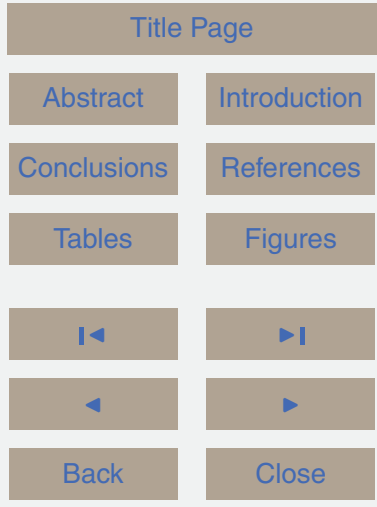

Full Screen / Esc

Printer-friendly Version

Interactive Discussion 


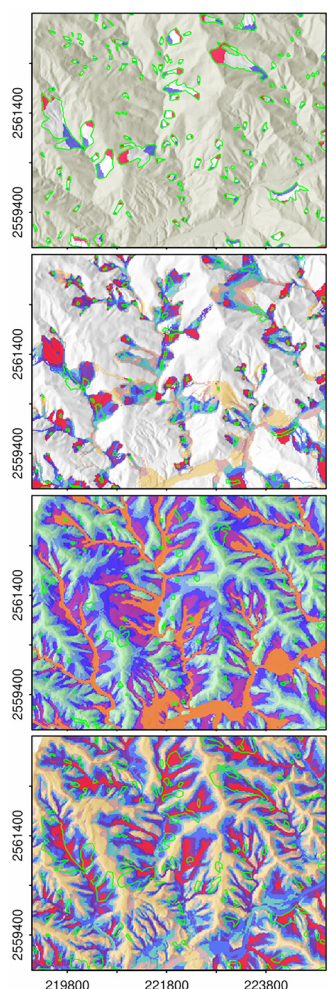

(a) Inv. TON ODA - OIA (c) $P_{1}^{*}$
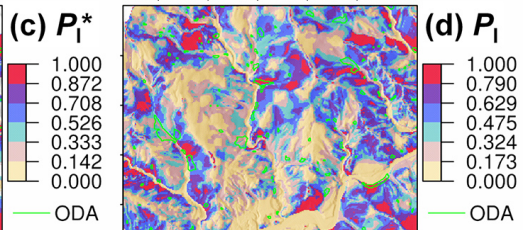

(e) $Z$

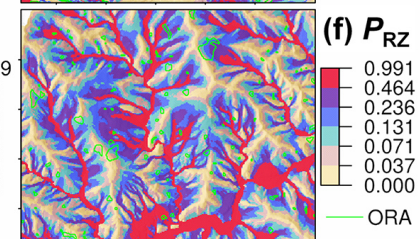

(g) $P_{L}$

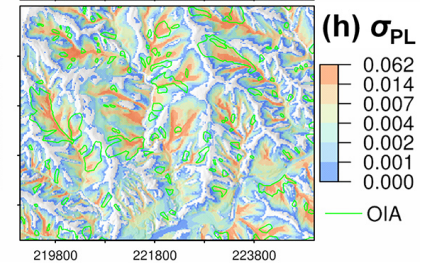

Figure 7. Set of results of the test $1 \mathrm{C}$. For readability, only a small subset of the test area (see Fig. 6) is shown. (a) Subsets of the landslide inventory into ORA and ODA. (b) Release probability $P_{\mathrm{R}}$. (c) Impact probability $P_{1}^{*}$ related to the observed landslides. (d) Impact probability $P_{1}$ related to all possible release pixels. (e) Area of the possible release zone $Z\left(\mathrm{~km}^{2}\right)$ related to each impact pixel. (f) Zonal release probability $P_{\mathrm{RZ}}$. (g) Integrated spatial landslide probability $P_{\mathrm{L}}$ (h) Standard deviation of $P_{\mathrm{L}}, \sigma_{\mathrm{PL}}$.

\section{NHESSD}

3, 5677-5715, 2015

Integrated statistical modelling of spatial landslide probability

M. Mergili and H.-J. Chu

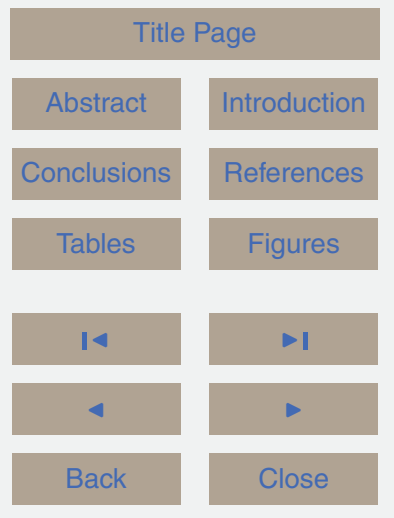

Full Screen / Esc

Printer-friendly Version

Interactive Discussion 

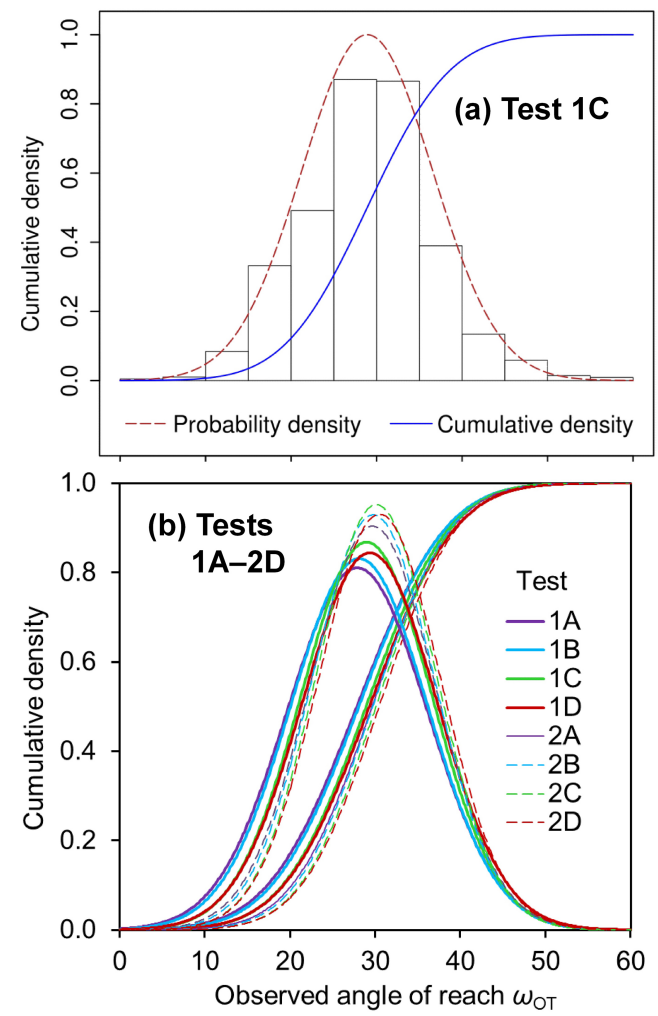

\section{NHESSD}

3, 5677-5715, 2015

Integrated statistical modelling of spatial landslide probability

M. Mergili and H.-J. Chu Title Page

Abstract

Introduction

Conclusions References

Tables Figures

14

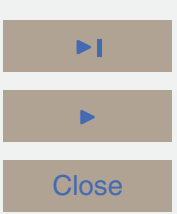

Back

Close

Full Screen / Esc

Figure 8. Gaussian probability density functions and cumulative density functions (CDFs) of the observed angle of reach $\omega_{\mathrm{OT}}$ (see Fig. 4). (a) Functions and histogram exemplified with test $1 \mathrm{~A}$. (b) Functions for the tests $1 \mathrm{~A}-2 \mathrm{D}$ (the functions for the tests $3 \mathrm{~A}-\mathrm{D}$ correspond to those for the tests $1 A-D)$.

Printer-friendly Version

Interactive Discussion 

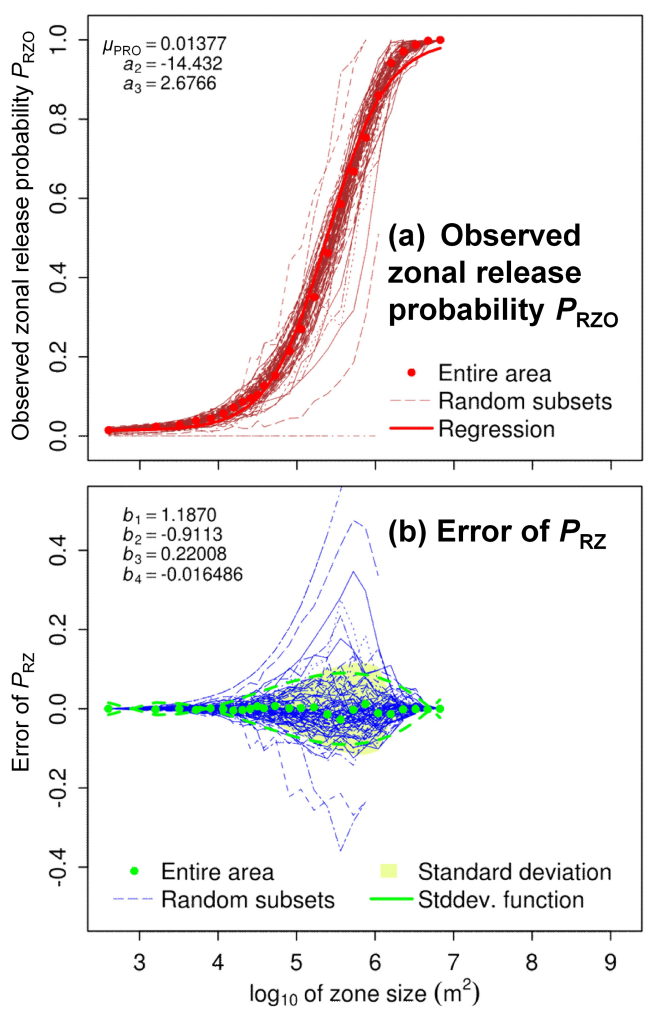

\section{NHESSD}

3, 5677-5715, 2015

Integrated statistical modelling of spatial landslide probability

M. Mergili and H.-J. Chu Title Page

Abstract Introduction

Conclusions

References

Tables Figures

14

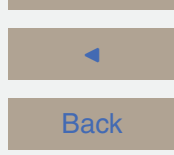

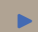

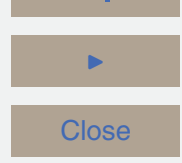

Full Screen / Esc

Figure 9. Zonal release probability (see Fig. 3). (a) Observed zonal release probability $P_{\mathrm{RzO}}$ derived with Test $1 \mathrm{C}$. Note that the value of $\mu_{\mathrm{PRO}}$ does not exactly correspond to the fraction of OP pixels in the zones $A, B$ and $D(0.0125$; see Table 3$)$ due to the effects of random sampling. (b) Error of $P_{\mathrm{RZ}}$ with standard deviation function.

Printer-friendly Version 


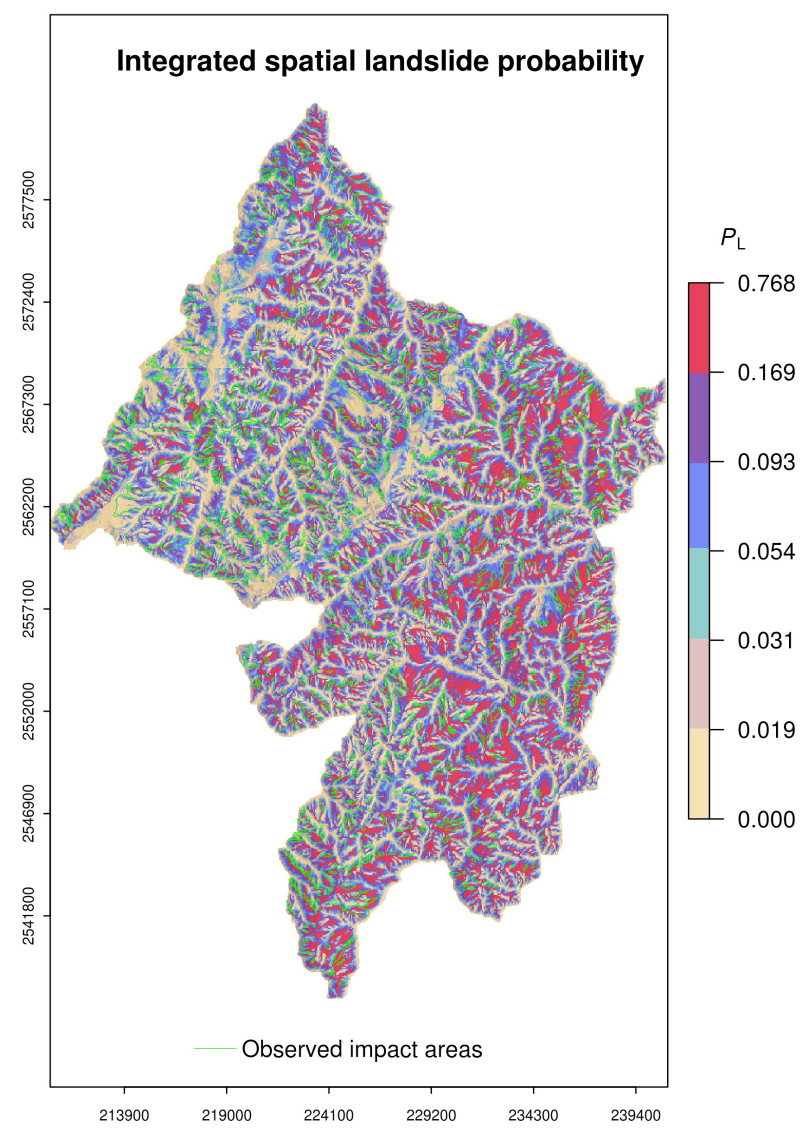

\section{NHESSD}

3, 5677-5715, 2015

Integrated statistical modelling of spatial landslide probability

M. Mergili and H.-J. Chu

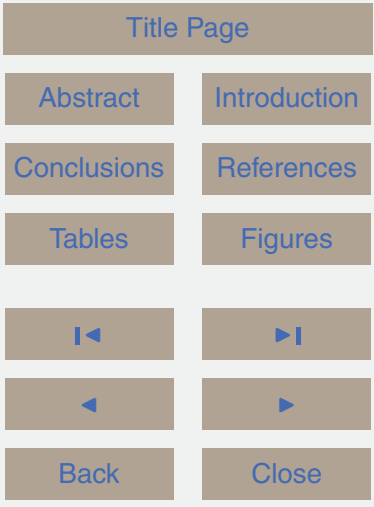

Full Screen / Esc

Printer-friendly Version

Figure 10. Integrated spatial landslide probability $P_{\mathrm{L}}$ for the entire test area. The results of the tests $1 \mathrm{~A}, 1 \mathrm{~B}, 1 \mathrm{C}$ and $1 \mathrm{D}$ are combined into one map.

Interactive Discussion 

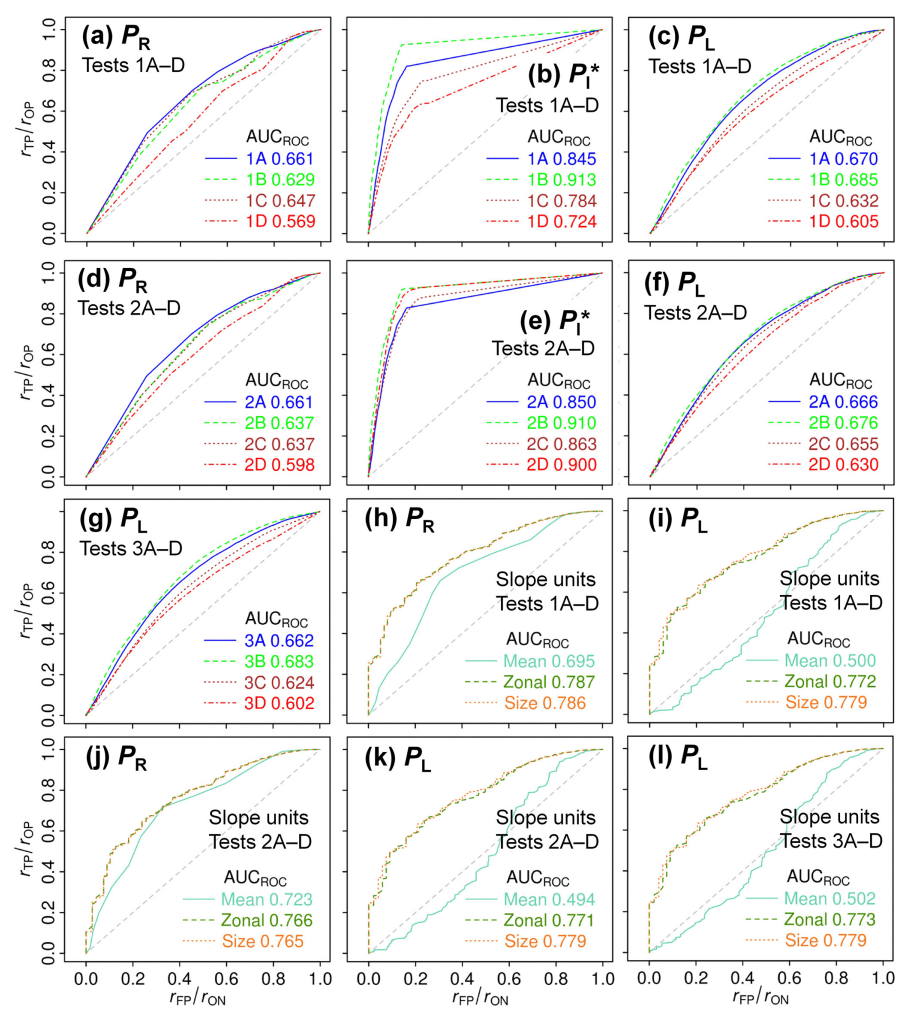

Figure 11. ROC Plots relating the model results for the MEAs of all tests to the relevant observations. (a-c) $P_{\mathrm{R}}, P_{\mathrm{l}}$ and $P_{\mathrm{L}}$ yielded with the tests $1 \mathrm{~A}-\mathrm{D}$, pixel level. (d-f) $P_{\mathrm{R}}, P_{1}$ and $P_{\mathrm{L}}$ yielded with the tests $2 \mathrm{~A}-\mathrm{D}$, pixel level. (g) $P_{\mathrm{L}}$ yielded with the tests $3 \mathrm{~A}-\mathrm{D}$, pixel level. (h-k) $P_{\mathrm{R}}$ and $P_{\mathrm{L}}$ yielded by combining the results for the sets of tests $A-D$, evaluated at the level of slope units. Besides the mean value of the probability for each slope unit, also the zonal probability and the size of the slope unit are considered.

\section{NHESSD}

\section{3, 5677-5715, 2015}

Integrated statistical modelling of spatial landslide probability

M. Mergili and H.-J. Chu

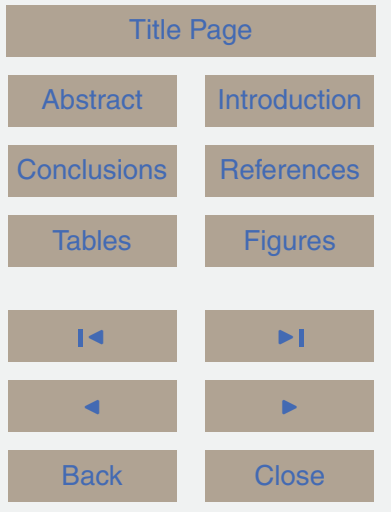

Full Screen / Esc

Printer-friendly Version

Interactive Discussion 